D.O.I: $10.3895 / \mathrm{S} 1808-04482012000200001$

\title{
PLANEJAMENTO E CONTROLE DAS OPERAÇÕES: MODELOS, METODOLOGIAS, PROCESSOS E TÉCNICAS
}

\section{OPERATIONS PLANNING AND CONTROL: MODELS, METHODOLOGIES, PROCESSES AND TECHNIQUES}

\author{
Everaldo Antonio Rutana Pereira ${ }^{1}$; Silvana Pereira Detro ${ }^{2}$; Edson Pinheiro de Lima ${ }^{3}$; Sergio \\ Eduardo Gouvea da Costa ${ }^{4}$ \\ ${ }^{1}$ Pontifícia Universidade Catolica do Paraná - PUCPR - Curitiba - Brasil \\ everaldo@rodoparana.com.br \\ ${ }^{2}$ Pontifícia Universidade Catolica do Paraná - PUCPR - Curitiba - Brasil \\ silvana.detro@pucpr.br \\ ${ }^{3}$ Pontifícia Universidade Catolica do Paraná - PUCPR - Curitiba - Brasil \\ Universidade Tecnológica Federal do Paraná - UTFPR - Curitiba - Brasil \\ e.pinheiro@pucpr.br \\ ${ }^{4}$ Pontifícia Universidade Catolica do Paraná - PUCPR - Curitiba - Brasil \\ Universidade Tecnológica Federal do Paraná - UTFPR - Curitiba - Brasil \\ s.gouvea@pucpr.br
}

\begin{abstract}
Resumo
Atualmente, as empresas estão inseridas em um ambiente complexo e dinâmico e para dar conta destes, devem desenvolver sistemas flexíveis para a gestão das suas operações, bem como acompanhar as mudanças no ambiente de negócios. Este artigo buscar identificar lógicas que integrem os diferentes modelos, metodologias, processos e técnicas para o planejamento e controle das operações de empresas de manufatura. A pesquisa desenvolvida é natureza exploratória e utiliza um questionário online para a condução de uma sondagem junto a um grupo específico de empresas. Pode-se classificar a pesquisa como um survey exploratório do tipo eletrônico. As empresas estudadas são sócias mantenedoras do Sindicato dos Metalúrgicos de Curitiba (SINDIMETAL) e constituem um total de 180 empresas pertencentes ao setor metal-mecânico. Da pesquisa realizada foram identificados três agrupamentos de lógicas para o planejamento $e$ controle de operações, nominadas como: 'Desdobramento', 'Qualidade' e 'Integração'.
\end{abstract}

Palavras-chave: modelos de gestão; planejamento e controle; gestão da produção; gestão estratégica de operações.

\section{Introdução}

A atualidade é marcada por uma realidade empresarial que se apresenta marcada pela globalização dos mercados, acirramento da competição, reforma dos Estados e um rápido avanço tecnológico. Tais elementos vêm provocando questionamentos e reflexões sobre os atuais conceitos 
e metodologias de gestão empresarial. Sendo assim, a crescente competitividade do mercado e a concorrência cada vez mais acirrada estão levando as empresas a repensar suas estratégias, especialmente no que tange ao planejamento de suas operações (HERZOG et al, 2009; VERBETEEN et al, 2009; HERATH, 2007; JONSSON e MATTSSON, 2003; KUMAR e MEADE, 2002).

É neste sentido que autores como Mula et al (2006), Palanisamy (2005) e Oliveira (2001) estabelecem que planejar é, antes de qualquer coisa, decidir antecipadamente. Portanto, o planejamento corresponde a uma série de decisões tomadas anteriormente ao momento da ação, correspondendo a um conjunto de decisões tomadas em um momento inicial para implementação posterior, onde devem ser consideradas as incertezas em cada elemento da cadeia de alternativas a serem implementadas.

A elaboração do planejamento é uma atividade complexa, envolvendo vários atores que são responsáveis por diferences funções organizacionais. Tais funções integram atividades do chão de fábricas às camadas mais estratégicas da empresa (HELO et al, 2008; TSENG et al, 2008; WATSON et al, 2007). Assim, para a sua elaboração é necessário identificar o que os diferentes stakeholders esperam de seus envolvimentos com a empresa. Atkinson et al (2007) destacam que “as expectativas dos stakeholders tornam-se os objetivos primários da empresa", sendo que o segundo passo do planejamento é escolher uma estratégia para alcançar tais objetivos primários da empresa.

Certos autores justificam o esforço de planejamento não só como uma forma de lidar com as incertezas e por consequência reduzir o risco percebido, das mudanças no ambiente de negócios provocadas pela globalização, pelo aumento da competição ou pela introdução de novas tecnologias. Estes autores destacam que a essência do planejamento está em sistematizar a produção de bens e serviços que mobilizam uma série de recursos em diferentes processos e atividades (JONSSON e MATTSSON, 2003, OLIVEIRA, 2001, NIETO et al, 1999; DOUMEINGTS et al, 1992).

Outros especialistas nas disciplinas de estratégia e planejamento estabelecem a atividade de planejar como decidir antecipadamente o que fazer, de que maneira fazer, quando fazer e quem deve fazer. O planejamento constitui um conjunto de decisões no momento presente, tendo como referência a construção de uma futuro desejado (SMITH e BOYNS, 2005; KOONTZ e O’DONELL, 1995; GLAUTIER e UNDERDOWN, 1991).

Contudo, para que as decisões tomadas no planejamento tornem-se ações efetivas é necessário que se desenvolva uma atividade de controle. Para Herzog et al (2009), Atkinson et al (2007) e Herath (2007), as atividades associadas ao controle são um conjunto de processos, técnicas, procedimentos e ferramentas que os colaboradores de uma empresa utilizam para mantê-la 
na direção e trajetória que conduzam ao alcance de seus objetivos.

O controle tem a função de retroalimentar o sistema de gestão. Para Atkinson et al (2007) a duração do controle é definida pela relação temporal entre o processo e o objeto do controle, e que seu ciclo de vida será a sua própria realização, visto que a partir desse momento o controle gera um feedback que inicia um novo processo de planejamento.

Pinheiro de Lima et al (2008) e Vasconcelos Filho e Machado (1994) afirmam que o controle é um instrumento da gestão estratégica capaz de direcionar e impulsionar os esforços individuais para alcançar objetivos e metas organizacionais, fazendo com que o sistema evolua através de processos de aprendizagem adaptativos e gerativos.

A partir das considerações introdutórias apresentadas, pode-se verificar que o objetivo principal deste artigo é o estudo de diferentes abordagens utilizadas pelas organizações para desenvolver os seus sistemas de planejamento e controle. Particularmente, o foco de atenção do trabalho é a função 'operações'. A identificação de tais modelos é conduzida de tal forma que um dos resultados do trabalho é a proposição de uma classificação para tais modelos.

As abordagens para o planejamento e controle das operações pesquisadas neste artigo são agrupadas de acordo com o seu 'modo' de planejar e controlar o sistema de gerenciamento das operações de produção de bens e serviços de uma empresa. Para construir um conjunto de tipos para classificar as abordagens utilizadas, foram utilizados os seguintes elementos: modelos, aqui determinados como estruturas de referência normativas que devem ser seguidas para o atendimento dos objetivos estratégicos; metodologias representadas por um conjunto de estratégias que devem ser seguidas para a execução do planejamento e do controle das operações; processos que são compostos pelos fluxos e racionalidades das atividades de planejamento e controle; e técnicas que, via procedimentos específicos, garantem a execução das atividades de planejamento e controle.

Uma sondagem foi realizada junto a 180 empresas cadastradas como sócias do Sindicato dos Metalúrgicos de Curitiba - SINDIMETAL, buscando verificar a aderência das práticas de planejamento de controle das operações adotadas e a classificação desenvolvida com base na literatura pesquisada.

\section{Da estratégia de operações}

Pilkington e Meredith (2009), em um estudo da literatura publicada em gestão de operações nos periódicos Journal of Operations Management (JOM), the International Journal of Operations and Production Management (IJOPM) e Production and Operations Management (POM), no período 1980-2006, destacam que os estudos em estratégia de operações têm sido os mais populares no período analisado na área de gestão de operações. Muito do que se desenvolve na área de gestão de operações tem como pano de fundo um contexto estabelecido pela estratégia de operações. 
O conceito de estratégia de operações começou a ser desenvolvido por Skinner (1969) na medida em que destacava que a relação entre a função manufatura e o sucesso da empresa é crítica e sensível. Muito embora, isto não fosse percebido pela maioria dos gerentes, que adotavam um conceito simplificado do que seria uma boa operação de manufatura, ou seja, baixos custos e alta produtividade.

Segundo Skinner (1969), o gerenciamento da manufatura era visto pelos gerentes de topo como uma rotina tediosa e cheia de detalhes, o que fazia com que se afastassem da área, deixando as decisões de manufatura com engenheiros e especialistas que não tinham conhecimento da estratégia da empresa. Por isso, muitas das decisões tomadas em relação à manufatura limitavam as opções estratégicas da empresa, deixando-a em uma posição competitiva desfavorável, que poderia levar anos para ser modificada. Skinner (1969) ainda argumenta que a manufatura é geralmente percebida de forma simplificada no topo, gerenciada de forma incoerente no nível da planta e ensinada de forma não muito adequada nas escolas de administração.

Brown (1998) afirma que a manufatura é importante de duas formas: quando promove um 'ajuste estratégico', ou seja, foca esforços e recursos de modo que a estratégia de manufatura seja consistente com a estratégia de negócios; e quando desenvolve capacitações que podem ser utilizadas na criação de novas oportunidades. Slack et al (2002) chamam estes dois papéis da manufatura, respectivamente, de apoiador e direcionador da estratégia de negócios, e acrescentam um terceiro: 'implementador' da estratégia da firma, em que a manufatura torna a estratégia uma realidade.

Hill (1989) desenvolve os conceitos de critérios 'ganhadores de pedido' e 'qualificadores' para a estratégia de manufatura. Tais conceitos contribuem para os esforços estratégicos da empresa, apoiando as diversas maneiras pelas quais os produtos ofertados superem os dos competidores. Fundamentam o desenvolvimento das diferentes políticas relacionadas à função manufatura.

Platts (2007) sintetiza a definição de estratégia de operações como um padrão de decisões, de natureza estrutural e infra-estrutural, que determina a capacidade do sistema de operações e especifica como este irá operar para atingir um conjunto de objetivos estabelecidos para a função operações, sendo que estes derivam dos objetivos do negócio.

Entendido o contexto da estratégia de operações, podem ser apresentadas algumas abordagens para o desenvolvimento dos sistemas planejamento e controle da produção.

\section{Das diferentes abordagens de planejamento}

Há diversas abordagens e modelos desenvolvidos para a gestão estratégica das operações. Zilbovicius (1999) considera que tais modelos exercem um papel fundamental para justificar a 
aplicação de determinadas técnicas e princípios, na medida em que tais modelos são adotados e acabam por se adaptar às condições concretas em que operam cada organização produtiva. Para este autor um modelo é visto como uma forma de solucionar os problemas de eficiência e de eficácia colocados para a organização, buscando uma teoria local para a efetividade, na medida da ação e de sua especificação.

Ao se buscar na literatura uma definição para modelos, metodologia, processo e técnicas, verifica-se a existência de diferentes formas de análise e conceituações relacionadas aos termos. Dentro disso, faz-se necessário uma revisão detalhada destes itens para o correto posicionamento das abordagens utilizadas para Planejamento e Controle de operações.

De acordo com Yourdon (1997) entende-se como metodologia uma série recomendada de passos e procedimentos que devem ser seguidos para obter-se o desenvolvimento de um sistema de informação. Já para Avison e Fitzgerald (1997), é o conjunto formado por procedimentos, técnicas e ferramentas que auxiliará os responsáveis no desenvolvimento da estratégia. Uma metodologia consistirá de fases, cada uma consistindo de sub-fases, que orientarão estes responsáveis na escolha das técnicas que deverão ser mais apropriadas a cada estágio do projeto e também auxiliá-los a planejar, gerenciar, controlar e avaliar o projeto como um todo.

Maddison apud Avison e Fitzgerald (1997) define metodologia como sendo um conjunto recomendado de filosofias, fases, procedimentos, técnicas, regras, ferramentas, documentação, gerenciamento e treinamento para o desenvolvimento de um sistema. Importante analisar que, este autor, apresenta neste conceito a inclusão de filosofia, que são teorias que norteiam os objetivos e procedimentos de uma metodologia. Assim, foi utilizado o termo Metodologia, para o agrupamento dos grupos que possuem formas estruturais e passos a ser seguidos para o atendimento do seu objetivo final, neste caso, o de Planejar e Controlar.

As técnicas e ferramentas caracterizam as metodologias, assim, estão relacionadas entre si. Podemos conceituar uma técnica com um modo de fazer uma atividade no processo de operações. Percebe-se que uma técnica pode ser utilizada em diversos processos. Cada técnica pode utilizar uma ou mais ferramentas e ainda, muitas técnicas são utilizadas em várias metodologias, fazendo com haja uma integração das técnicas com os outros grupos conceituais.

Galliano (1979) apresenta que uma técnica é o modo de fazer de forma mais segura e mais perfeita algum tipo de atividade, assim, acaba se tornando uma fase essencial para o correto Planejamento e Controle de Operações.

Outra abordagem utilizada para o planejamento e controle de operações é um Modelo, que pode ser considerado também uma representação simplificada da realidade. O papel de um modelo pode ser apresentado como sendo um ensaio, uma aproximação, uma maqueta mais ou menos abstrata, permitindo assim, uma melhor interpretação das variáveis que podem um grupo estudado. 
Para Zilbovicius (1997), os modelos têm um papel fundamental na difusão de práticas, ainda que delas se diferencie, por ser um processo abstrato. A aceitação de um modelo dependerá de sua validação, só é legítimo se é válido. Os modelos estabelecem um modo de pensar, abordar e articular os problemas organizacionais e desempenham um papel de referências, ou seja, operam como prescrição para os agentes que tomam decisão a respeito de práticas a serem empregadas nas operações e processos organizacionais. Ainda de acordo com Zilbovicius (1997) um modelo é visto como uma forma de solucionar os problemas de eficiência colocados à organização, buscando uma teoria local para a efetividade, na medida da ação e de sua especificação.

Quando buscamos a caracterização de processos, verifica-se que nas organizações, um processo se constituiu no elemento fundamental pelos quais as empresa necessitam cumprir para entregar seus produtos e serviços aos clientes. Rotondaro(2004) apresenta o processo como sendo um sequencia organizada de atividades, que transforma as entradas dos fornecedores em saídas com valor agregado para os clientes. Já para Salerno (1998) um processo deve ser entendido como uma cooperação de atividades distintas para a realização de um objetivo global, sendo repetido de maneira recorrente dentro da empresa.

Um processo irá compor na sua execução, tudo aquilo que é fornecido pela organização. É neste sentido que Valeriano (1998) define o processo como sendo um conjunto de recursos e atividades inter-relacionadas que transformam insumos em produtos finais.

Assim, após a análise da literatura, embora ela seja rica em conceitos e cada autor apresenta a sua visão sobre um processo, percebe-se que todos estão relacionados a atividades e tarefas, envolvem recursos de entrada, transformação e produtos de saída, transformando esses recursos de entrada em produtos com valor agregado e disponibilizando os mesmos para um cliente interno ou externo.

Tratadas algumas definições e conceitos, estes ajudam a entender o desenvolvimento e apresentar base teórica para a realização de uma sondagem buscando a distribuição das abordagens nos grupos de Modelos, Técnicas, Metodologias ou Processos. Um modelo de gestão é concebido a luz de uma determinada abordagem. Os modelos podem ser categorizados levando-se em consideração as metodologias, processos e técnicas que são utilizados para o seu desenvolvimento, implementação e uso (MULA et al, 2006; JONSSON e MATTSSON, 2003; DOUMEINGTS et al, 1992).

\subsection{Dos modelos de planejamento e controle}

Determinados autores apresentam o Balanced Scorecard (BSC) como uma primeira tentativa de se sistematizar o desenvolvimento de um sistema de avaliação de desempenho que enfoca os objetivos da empresa, coordena a tomada de decisão individual e provê uma base para o 
aprendizado organizacional. Constitui, portanto, um modelo para a gestão estratégica que pode ser tanto aplicado nos níveis funcionais (e.g. produção, marketing, finanças etc.), como também no nível das unidades de negócio (CHAVAN, 2009; ATKINSON, et al, 2007; ANDERSEN et al, 2004; GARCIA-CEBRIAN e LOPEZ-VIEGA, 2002; KAPLAN e NORTON, 1992).

O Business Plan é um instrumento de planejamento formal que sistematiza o desenvolvimento da estratégia na forma planos e metas. Trabalha essencialmente com uma causalidade pré-determinada entre estratégia, planejamento, ação e resultados que ciclicamente interagem entre si (HVOLBY e TRIENEKENS, 2010; HERZOG et al, 2009; VERBEETEN e BOONS, 2009; JONSSON et al, 2007; KOVÁCS e PAGANELLI, 2003; RENTES et al, 1999; SAHLMAN, 1997; DOUMEINGTS et al, 1992).

O modelo de Produção Enxuta combina uma série de metodologias e técnicas de gerenciamento da produção que visam desenvolver elevados padrões de eficiência operacional. A produção enxuta visa, portanto, reduzir custos mediante a completa eliminação de desperdícios. $\mathrm{O}$ modelo é constituído de dois princípios direcionadores: o primeiro é o Just in time (JIT), produzir somente o que é necessário, na quantidade necessária e quando for necessário; o segundo é o Jidoka, fazer com que qualquer problema de produção seja imediatamente evidenciado e parar de produzir quando os desvios forem detectados (RIEZEBOS et al, 2009; WOMACK et al, 2004; OHNO, 1997; KELLER e KAZAZI, 1993).

Warnecke e Hüser (1995) definem a Produção Enxuta como um sistema de medidas e métodos que, quando adotados simultaneamente, trazem benefícios não apenas para a função manufatura, mas para a empresa como um todo.

O Desdobramento pelas Diretrizes surge dentro do movimento da qualidade como um modelo de gestão que visa disseminar, por toda a organização, a visão e os objetivos institucionais, definindo estratégias e dimensionando recursos e medidas (indicadores) para as metas propostas e, conseqüentemente, gerando ações programadas. O sistema como um todo é revisado de forma periódica e contínua, formando um ciclo estratégico de PDCA (Plan, Do, Check e Act) (KULL e WACKER, 2010; MATOOK e INDULSKA, 2009; RAGHUNATHAN et al, 1997; CAMPOS, 1996; FORZA, 1995).

Campos (1996) estabelece que uma 'diretriz' é uma meta acompanhada de um plano para atingi-la, entendendo por 'meta' um objetivo gerencial associado a um valor e a um prazo. Desdobrar uma diretriz significa dividi-la em várias outras diretrizes sob a responsabilidade de outras pessoas. O desdobramento caracteriza as relações de causa e efeito entre planejamento, ações e resultados.

A Gestão da Qualidade Total (TQM) fundamenta-se nos seguintes princípios: satisfação dos clientes; constância dos propósitos e compromisso da alta administração com a qualidade; 
desenvolvimento dos recursos humanos de uma empresa via treinamento, educação e delegação de responsabilidades aos seus funcionários; gerência participativa e por processo; garantia da qualidade e aperfeiçoamento contínuo de produtos/processos, disseminação padronização das informações e não aceitação de erros. Basicamente, o sistema de gestão da qualidade total trabalha fundamentado nos princípios de melhoria contínua e controle de variância (erros) em um ciclo PDCA estabelecido no nível do chão de fábrica, ou seja, no fluxo da cadeia de valor de uma empresa (RAMIREZ et al, 2010; MARTÍNEZ-COSTA et al, 2009; FERNANDES et al, 2009; SLACK et al, 2002; HUARNG e CHEN, 2002; ALLIPRANDINI e TOLEDO, 1993).

Ainda no âmbito da qualidade, há os chamados prêmios nacionais de qualidade, que no caso do Brasil é concedido anualmente pela Fundação Prêmio Nacional da Qualidade (FPNQ). Internacionalmente, destacam-se o Malcolm Baldrige National Quality Awards (MBNQA), o European Quality Award (EQA-EFQM), o Japanese Deming Prize (DP) e o Japan Quality Award (JPA). Estes prêmios desenvolvem modelos de referência que orientam o processo de avaliação. As empresas, no entanto, vêm utilizando estes modelos como referências para o projeto dos seus sistemas de gestão e, sendo assim, tais modelos constituem referências normativas (BOU-LLUSAR et al, 2009; FLYNN e SALADIN, 2006; DA SILVA et al, 2005; CAUCHICK MIGUEL et al, 2004; TAN, 2002).

Identificados os modelos básicos para gestão e, particularmente, modelos adotados para a gestão e organização da produção, pode-se desenvolvê-los via metodologias, processos e técnicas.

\subsection{Metodologias de planejamento e controle}

Diversas metodologias vêm sendo aplicadas para viabilizar os modelos anteriores. O 'Custeio Baseado em Atividades' (ABC) que surgiu nos EUA, na década de 80, formalizado pelos professores Kaplan e Cooper (1997). Kaszubski e Ebben (2004), Driver (2001), No e Kleiner (1997), Nakagawa (1995), Cogan (1994) estabelecem que o ABC constitui uma metodologia orientadora para o design de um sistema de gestão.

Os sistemas ERP (Enterprise Resource Planning) são sistemas de gestão empresarial, caracterizados, principalmente, por abranger um escopo amplo de funcionalidades, pela capacidade de adaptação em vários tipos de empresas e pela integração de seus dados. Não deixam de constituir uma metodologia para a integração da informação e para o estabelecimento de um fluxo para os processos decisórios ou de gestão (VAN NIEUWENHUYSE et al, 2011; SAMARANAYAKE, 2009; HELO et al, 2008; LIN et al, 2007; KAKOURIS e POLYCHRONOPOULOS, 2005; CORONADO et al, 2002; RESENDE E ABREU, 2000; CORRÊA et al, 2001; KELLER e TEUFEL, 1998). 
Just in Time não é apenas uma técnica, como é conhecido em algumas organizações, mas sim, uma completa filosofia que inclui aspectos de gestão de materiais, gestão da qualidade, organização física dos meios produtivos, engenharia de produto, organização do trabalho e gestão de recursos humanos. Constitui, portanto, uma metodologia para a organização e gestão da produção (MISTRY, 2005; MELCHER et al, 2002; ONWUBOLU e MHLANGA, 1997; FLYNN et al, 1997).

Apresentadas as metodologias podem ser identificados processos para o planejamento e controle da produção.

\subsection{Dos processos para planejamento e controle}

O planejamento e controle da produção é um macro processo que compreende a elaboração de planos para orientar a produção e servir de guia para seu controle, determinando o quê, quanto, como, onde, quem e quando vai ser produzido. O processo de planejar deve ser fundamentado numa visão sistêmica, ou seja, no entendimento dos fatos ocorridos no passado e no presente, e suas respectivas influências para a tomada de decisão para obter, no futuro, os resultados planejados. Também, deve englobar todos os atores envolvidos com a cadeia de valor e com a rede de operações produtivas. Há, constitutivamente, uma hierarquia entre os processos de planejamento estratégico da produção, o planejamento mestre da produção e a programação da produção. No que se refere a gestão ou controle, há laços de realimentação que se estabelecem nas três camadas hierárquicas citadas (MELCHER et al, 2002; CORREAA et al, 2001; DOUMEINGTS et al, 1992; MACHLINE et al, 1984).

O estudo dos processos que definem como a produção é organizada e gerenciada pode apoiar-se em modelos previamente prescritos na documentação dos sistemas de gestão da produção. As diferentes certificações estabelecem padrões e o escopo para a construção dos modelos de referência. A análise dos processos permite uma revisão permanente, estabelecendo um círculo virtuoso de melhoria contínua. Tanto nos modelos baseados na disciplina da qualidade, como também nos que se fundamentam em tecnologia de informação, o estabelecimento e mapeamento dos fluxos de processo é tarefa básica para o desenvolvimento destes modelos (MARTíNEZCOSTA et al, 2009; LIN et al, 2007; BARBER et al, 2003; YAHYA e GOH, 2001).

Os processos mobilizam uma série de recursos nas diferentes atividades que os compõem. A maneira como tais recursos criam valor é definida por um determinado conjunto de técnicas.

\subsection{Das técnicas de planejamento e controle}

O 'Desdobramento da Função Qualidade’ é uma técnica tem por objetivo principal assegurar que o projeto de um produto ou serviço atenda às necessidades de seu cliente (CARNEVALLI e 
MIGUEL, 2008).

Outra técnica que vem se difundindo no âmbito da gestão dos sistemas de produção é a 'Análise de Modo e Efeito de Falha' (FMEA) que constitui uma análise detalhada das disfunções que podem ser produzidas nos componentes de um sistema. É uma técnica para o gerenciamento de risco, identificando os possíveis modos de falhas de um dado produto ou processo, suas respectivas causas, bem como os efeitos destas sobre o cliente (SCHROEDER et al, 2008; KULVATUNYOU e WYSK, 2000; DIETER, 1991).

O Seis Sigma foi criado como forma de treinar e disseminar técnicas estatísticas de identificação, solução e controle de problemas em todos os níveis da organização. Fundamenta-se no controle de variância para produzir otimização nos processos e, desta forma, alcançar ganhos de qualidade, produtividade e de satisfação dos clientes (CHAKRAVORTY, 2009; KESSLER, 2004).

A técnica de 'Controle Estatístico de Processo' (CEP) fundamenta-se no uso de 'Cartas de Controle' para monitorar a variabilidade existente nos processos. Bischark e Trietsch (2007) estabelecem que as cartas de controle foram originalmente desenvolvidas para que os parâmetros do processo em estudo fossem conhecidos. As cartas de controle são usadas para detectar os problemas e, no seu tratamento, melhorar a qualidade, a produtividade e a confiabilidade do processo em análise.

O Business Brain (B2) é um exemplo de técnica incorporada aos 'Sistemas de Apoio à Decisão' (SAD). O B2 como é chamado, objetivamente, pretende permitir aos gerentes de operações acesso a informações internas e externas à empresa, atualizadas em tempo real, apresentando de forma clara e precisa os indicadores de desempenho da (SPRAGUE e WATSON, 1996).

A 'Tecnologia de Produção Otimizada' (OPT) é uma técnica de gestão de produção que se fundamenta na 'Teoria das Restrições' e foi desenvolvida para focalizar a atenção nas restrições de capacidade ou gargalos da produção (WATSON et al, 2007).

Identificados os elementos básicos que constituem os modelos de produção, podem-se estudar as combinações entre os diferentes elementos apresentados.

\section{Da seleção dos grupos}

Para a construção dos agrupamentos das diferentes lógicas para o planejamento e controle das operações de uma empresa, observou-se que a revisão de literatura não seria suficiente para definir as diferentes combinações possíveis entre modelos, metodologias, processos e técnicas. E sendo assim, visando identificar tais grupos de lógica, foi desenvolvido e aplicado um questionário para a sondagem junto a um grupo de empresas filiadas ao Sindicato dos Metalúrgicos de Curitiba SINDIMETAL. 
A prática revela que em muitas situações modelos híbridos são empregados para a gestão das operações produtivas de uma organização e, este estudo, busca desenvolver um entendimento acerca dos modelos adotados (MARTÍNEZ-OLVERA, 2009).

\subsection{Da metodologia empregada}

A natureza da pesquisa é exploratória e utiliza um survey para descrever o comportamento de um conjunto de empresas em relação a adoção de modelos de gestão da produção. As técnicas utilizadas para análise dos resultados compreendem a estatística descritiva e análises de agrupamento ou cluster qualitativa e quantitativa.

A elaboração do questionário levou um tempo considerável devido à complexidade das questões e a necessidade de se extrair o maior número possível de informações em um tempo determinado. A primeira versão do instrumento de sondagem contava com cerca de 40 questões, estas questões eram abertas e investigavam diferentes momentos das organizações. Tendo este em mãos, fez-se um teste junto a um conjunto escolhido de empresas. Neste primeiro teste verificou-se que o instrumento de pesquisa estava com sérios problemas, as questões eram muito amplas, dificultando a coleta de informações. O principal problema era o tempo de resposta, verificou-se que este questionário levaria cerca de 60 minutos para ser respondido corretamente.

Revisou-se, portanto, o questionário reduzindo-o para 25 questões. Repetiu-se o exercício de preenchimento do questionário e percebeu-se que houve uma grande melhora no tempo de resposta e na clareza. Porém, observou-se que ainda não era o ideal, pois havia ausência de respostas em algumas questões. Partiu-se, então, para a terceira revisão, onde se reduziu o questionário a 10 questões, reformulando também o descritivo das questões para se extrair exatamente o necessário para o processo. Neste último teste foram 'validadas' definitivamente as questões. Após a tabulação das respostas verificou-se que o questionário de sondagem conseguiu extrair das empresas as informações necessárias.

As questões estão organizadas em quatro grupos. O 'Grupo 1' recupera dados cadastrais da empresa pesquisada. O 'Grupo 2' identifica o uso de metodologias, processos e técnicas para a gestão da qualidade. $\mathrm{O}$ 'Grupo 3' avalia as tecnologias de informação e comunicação utilizadas no planejamento e controle das operações. No 'Grupo 4' desenvolve-se uma avaliação de como os indicadores estratégicos da Organização são definidos e qual abordagem é utilizada para o acompanhamento dos mesmos, na gestão de operações. E finalmente, no 'Grupo 5' busca criar o relacionamento entre modelos, metodologias, processos e técnicas na forma de planos, ações e indicadores.

A sondagem realizada abrange um grupo de empresas localizadas em Curitiba e Região Metropolitana, dentro de um mesmo setor, o metal-mecânico. O estudo é de natureza exploratória e 
busca identificar diferentes agrupamentos de lógicas para o planejamento e controle da produção.

Este estudo foi efetuado via aplicação de um questionário de sondagem que segundo Semenik e Bamossy (1995), o levantamento administrado por questionários permite que o pesquisador reúna um grande volumes de dados a um custo relativamente baixo. As desvantagens deste meio são os baixos índices de resposta, a falta de possibilidade de esclarecimentos das perguntas e nenhuma certeza de que foi a pessoa certa que respondeu o questionário, o qual teve por objetivo a verificação das abordagens utilizadas pelas organizações pesquisadas para o Planejamento e Controle de seus processos produtivos.

O questionário foi respondido pelas empresas utilizando-se de um aplicativo, 'LimeSurvey', disponibilizado no endereço eletrônico http://surveys.produtronica.pucpr.br/. Foram enviados questionários para as 180 empresas cadastradas como sócias junto ao Sindicato dos Metalúrgicos de Curitiba - SINDIMETAL.

Dos 180 questionários enviados, cerca de 30 e-mails retornaram com erros como: endereço de e-mail inválido; responsáveis pela área de produção em período de férias; empresas que já encerraram suas atividades, mas ainda constam no quadro de sócios da entidade. Sendo assim, resultaram em 150 empresas acessadas.

O tempo de retorno das respostas foi cerca de um mês, sendo realizadas dentro deste período três chamadas.

\subsection{Dos resultados da sondagem}

Do total de empresas estudadas, foram recebidos 46 questionários completos, totalizando $30,66 \%$ como taxa de retorno, índice considerado satisfatório para este tipo de sondagem, dado o caráter exploratório e os meios empregados, ou seja, a combinação de e-mail e formulário online (HAMILTON, 2003; SHEEHAN, 2001).

A sondagem foi classificada de acordo com o porte da empresa, critério estabelecido pelos pesquisadores visando uma separação em grupos de análise com características semelhantes, medido nesta pesquisa através do número de colaboradores que cada empresa pesquisada possui. Tendo esses dados tabulados, dividiu-se o resultado em três categorias:

a) Empresas de pequeno porte: empresas que possuem até 30 colaboradores;

b) Empresas de médio porte: empresas que possuem de 31 à 150 colaboradores;

c) Empresas de grande porte: empresas que possuem mais de 151 colaboradores.

A distribuição de respostas por categoria é apresentada no Gráfico 1. Verifica-se que 43\% das empresas que responderam o questionário são classificadas como de grande porte, $37 \%$ como 
de médio porte e $20 \%$ como de pequeno porte. O total grande e médio porte, de $80 \%$ garante qualidade à sondagem, dada a provável complexidade e 'maturidade/evolução' do sistema de gestão.

Figura 1- Porte das Empresas Pesquisadas

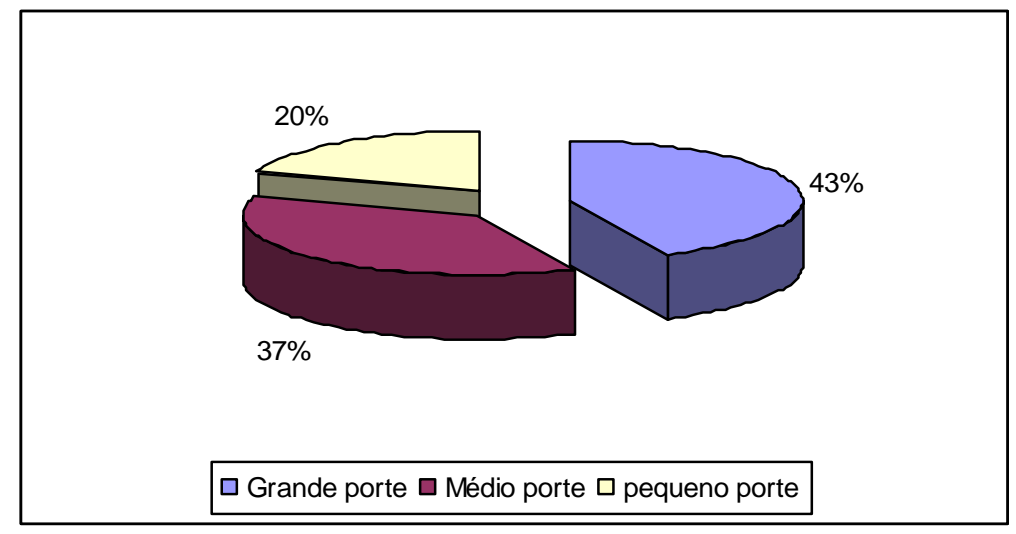

Fonte: Os autores (2012)

O Gráfico 2 demonstra que $72 \%$ dos respondentes à pesquisa, são gestores do processo produtivo das organizações, fato que também contribui para a qualidade das respostas.

Figura 2- Funções dos Respondentes

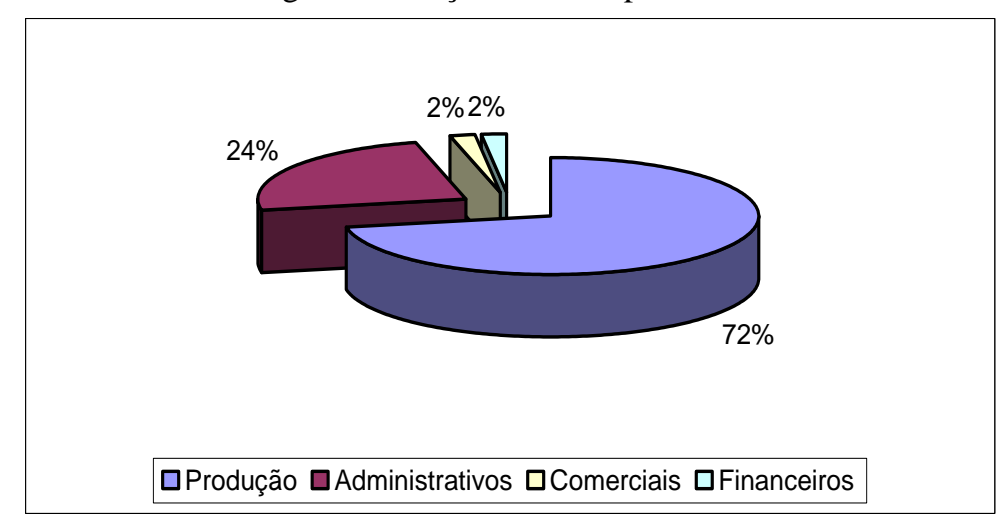

Fonte: Os autores (2012)

A análise dos modelos ou lógicas que seguem, estabelecem-se em um contexto estratégico. Sendo assim, o estudo dos sistemas de planejamento e controle é realizado no contexto da Estratégia de Operações.

A visão das empresas no que se refere à gestão da qualidade e a sua relação com os sistemas de planejamento e controle é recuperada neste conjunto de questões. Particularmente, procurando identificar a adoção de determinados modelos, processos ou técnicas.

Duas questões distintas foram propostas, a primeira identifica o nível de utilização de determinados elementos para a gestão da qualidade. O resultado é apresentado no Gráfico 3. 
Figura 3 - Elementos Identificados para a Gestão da Qualidade

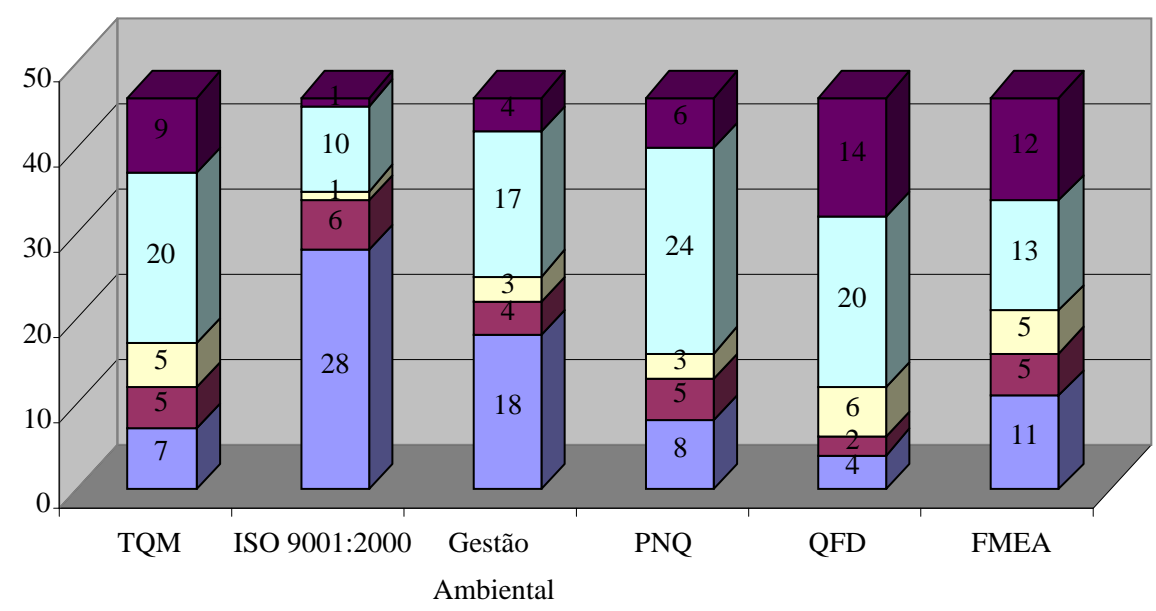

$\square$ Muito Utilizad $\square$ Utilizado $\square$ Pouco Utilizado $\square$ Não Utilizadq $\square$ Não conhecemos

Fonte: Os autores (2012)

Observa-se que um número representativo de empresas tem certificação ISO 9000, ou seja, identificaram-se 28 empresas (60\%). Técnicas como QFD e FMEA apresentam índices elevados de não conhecimento por parte das organizações.

A segunda questão proposta trata especificamente do modelo de planejamento e controle adotado. O resultado é apresentado no Gráfico 4.

Figura 4 - Modelo de planejamento e controle adotado

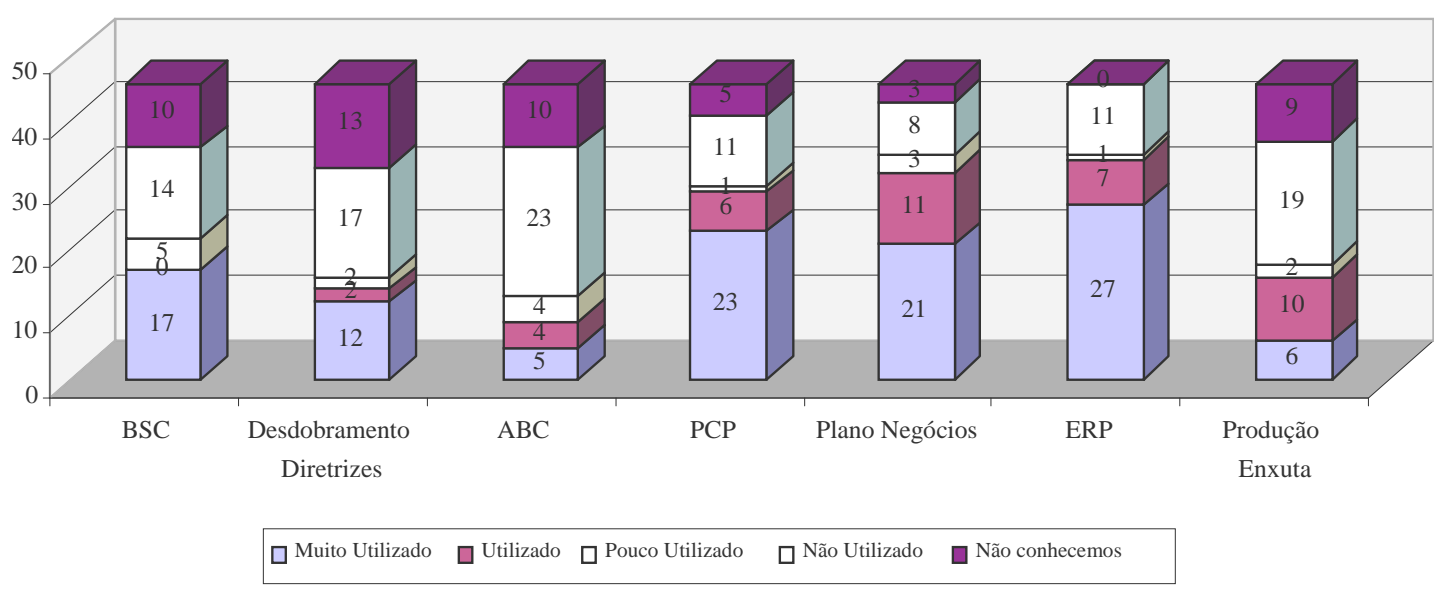

Fonte: Os autores (2012)

Ao se falar em gerenciamento do processo produtivo tem-se um número elevado de empresas que utilizam o ERP (Enterprise Resource Planning) como principal instrumento de gerenciamento da produção, sendo este uso identificado em 27 empresas (58\%). O modelo ABC, não é utilizado ou é desconhecido por cerca de $70 \%$ das empresas sondadas.

Observou-se uma tendência no uso de sistemas do tipo ERP, definindo a arquitetura tecnológica do sistema de gestão. A integração das bases de dados e a formalização dos processos 
de gestão são características importantes destes sistemas.

Primeiramente, verificou-se que $80 \%$ das empresas utilizam de um software para a integração de diversas funções das suas operações produtivas.

O Gráfico 5 apresenta o escopo de integração dos sistemas ERP adotados. Também se apresentam os níveis de dependência das diferentes funções envolvidas.

Figura 5 - Integração do sistema ERP

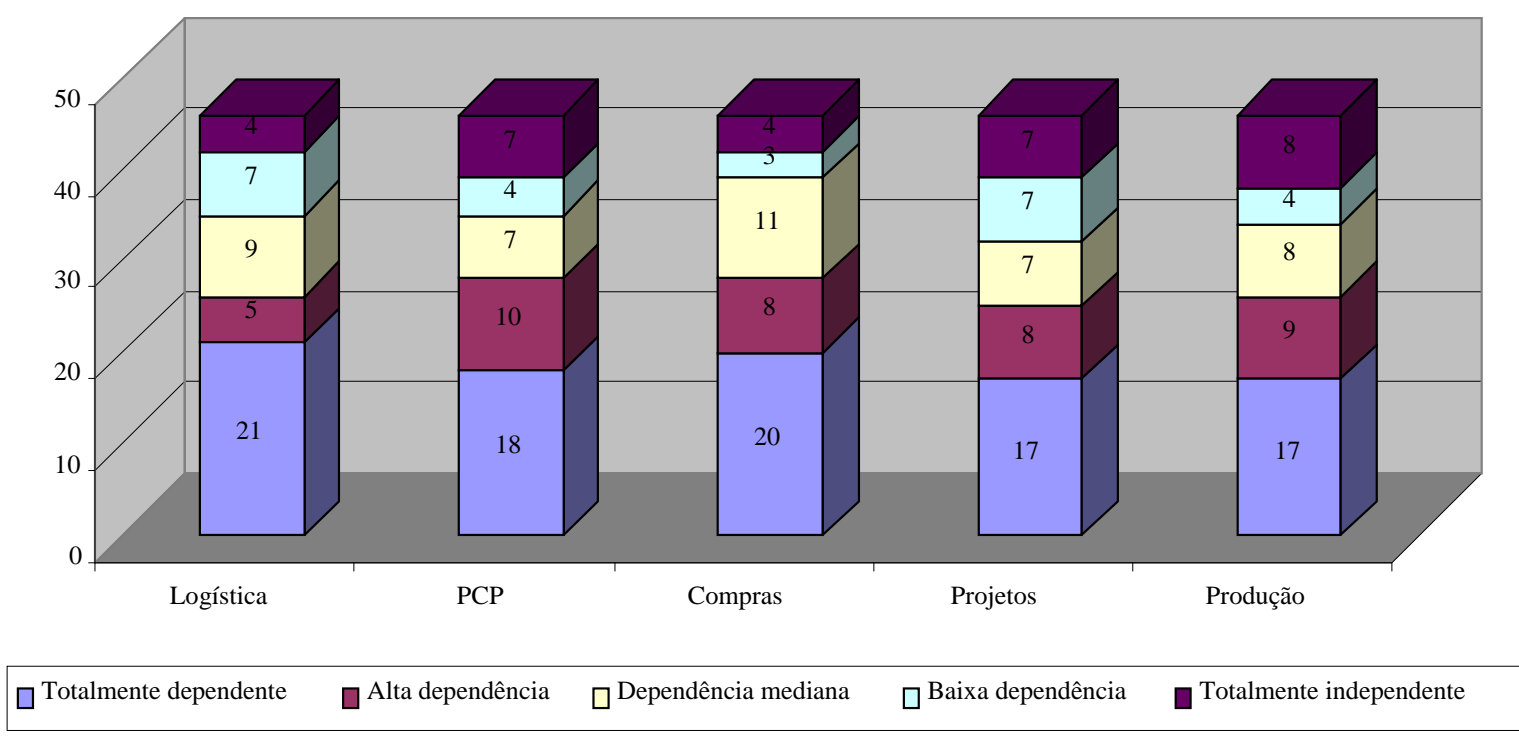

Fonte: Os autores (2012)

O sistema ERP é apresentado como arquitetura tecnológica básica para o gerenciamento e controle do processo produtivo, sendo utilizado pelas funções de Logística, Planejamento e Controle, Compras, Projetos e Produção. Conforme tabulação das respostas tem-se que em praticamente $37 \%$, as funções são totalmente dependentes dos sistemas ERP utilizados.

A função controle é um elemento importante dentro de um sistema de gestão da produção. $\mathrm{O}$ Gráfico 6 apresenta a forma como são geridos alguns indicadores relacionados às operações de uma empresa.

A sondagem delimitou um determinado conjunto de indicadores, tidos como fundamentais. Observa-se que para o controle de produção, a ação de controle é realizada em tempo real (on line) ou diariamente por $68 \%$ das empresas pesquisadas. 


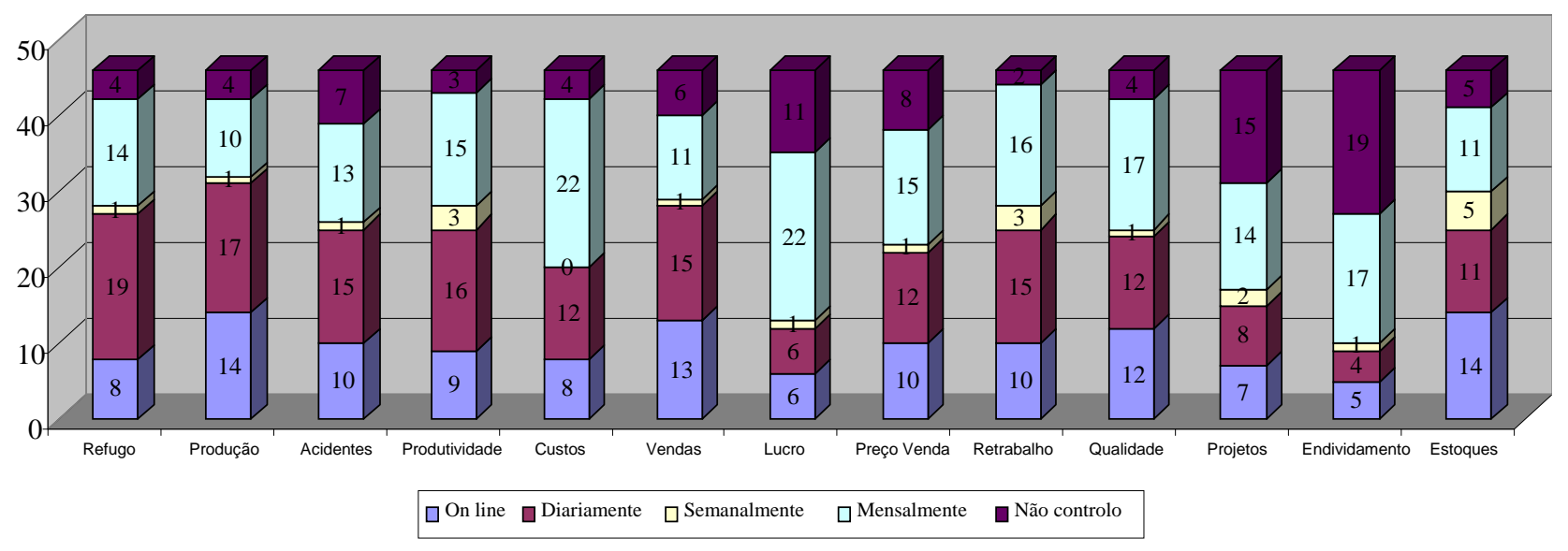

Fonte: Os autores (2012)

Destaca-se que para os entrevistados houve uma significante resultado 'não controlo, para indicadores como lucro (11 empresas), acompanhamento de projetos (15 empresas) e endividamento (19 empresas). Muito embora estes indicadores não estejam diretamente ligados a produção, os mesmos devem ser conhecidos pelos gestores. Este tipo de controle não é percebido pelos gestores.

O grupo de questões cujo objetivo principal é a explorar aspectos relativos à gestão estratégica da produção, procura identificar como são disseminados conceitos como 'visão estratégica', 'visão da manufatura', 'políticas de produção', 'diretrizes e metas de produção' dentro da organização. Também se preocupam em identificar como estes planos, metas e indicadores de resultado da produção são compilados e apresentados para os colaboradores.

A pesquisa demonstrou que $40 \%$ das organizações possuem um planejamento anual de metas e objetivos empresariais e de que estes são disseminados para área de produção. Há um monitoramento freqüente dos resultados e ações corretivas são conduzidas quando do não atendimento das metas.

Outra abordagem utilizada pelas organizações para disseminar as políticas das áreas funcionais da empresa são os informativos, utilizado por $30 \%$ das empresas pesquisadas. Geralmente estes informativos têm freqüência mensal e são apresentados para a organização como um todo. Destaca-se que em $28 \%$ das empresas pesquisadas, o modelo de planejamento e de desdobramento em metas específicas é do tipo 'top-down'

Do Gráfico 7, percebe-se que a forma mais utilizada pelas organizações para apresentar os resultados dos indicadores de desempenho ainda é a planilha eletrônica (planilha Excel), utilizada por $39 \%$ das empresas estudadas. Destaca-se que 16 empresas estão utilizando o BSC para acompanhamento e visualização dos resultados das operações produtivas. 

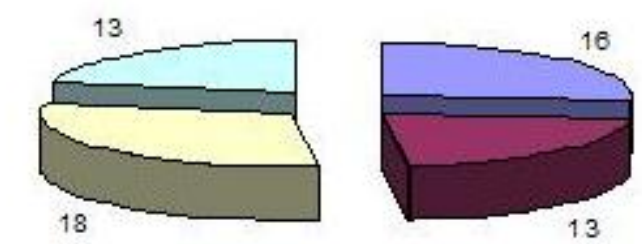

$\square$ BSC $\square$ ERP $\square$ planilha excel $\square$ painel de metas

Fonte: Os autores (2012)

Muitos sistemas de planejamento e controle utilizam dados da gestão da qualidade como uma importante fonte de informação. Para 35\% das empresas pesquisadas há uma integração de dados entre os sistemas de gestão da qualidade e os sistemas de planejamento e controle da produção.

São intrínsecos à arquitetura do sistema de planejamento e controle, os laços de realimentação e por conseqüência, estabelecem-se as condições necessárias para o desenvolvimento dos processos de melhoria contínua. $46 \%$ das empresas pesquisadas destacam que existem diversas atividades sistematizadas para a gestão da melhoria contínua, as equipes definem metas, atividades e prazos onde se empregam técnicas de identificação e solução de problemas como o ciclo PDCA, Diagramas de Espinha de Peixe, Programas Kaizen, FMEA etc. Para outros 22\% das empresas sondadas, não existe uma sistemática definida para gestão das melhorias, toda sugestão depende de recursos para ser levada a cabo. Em 17\% das empresas estudadas são realizadas diversas atividades que buscam melhoria contínua em aspectos identificados e significativos, muito embora, tais atividades não sejam identificadas como pertencentes a programas de melhoria, ou seja, o foco das ações dentro de um planejamento geral é a melhoria do desempenho das operações. Em 11\% das respostas, existe facilidade de se apontar necessidades de melhorias, muito embora não se tenha um tratamento sistematizado de tais ações. E finalmente, para $4 \%$ das empresas, as atividades são espontâneas em toda a empresa, no entanto, as principais ações vêm da área de gestão da qualidade que é a responsável última pelos programas de melhoria contínua.

Percebe-se uma grande diferença entre pequenas empresas e grandes empresas, o percentual de $46 \%$ é representado em sua grande maioria por grandes empresas em que a melhoria contínua é um processo formalizado.

Os fatores ganhadores de pedido também foram analisados durante a sondagem. O Gráfico 8 estabelece as dimensões consideradas como ganhadoras de pedido. 


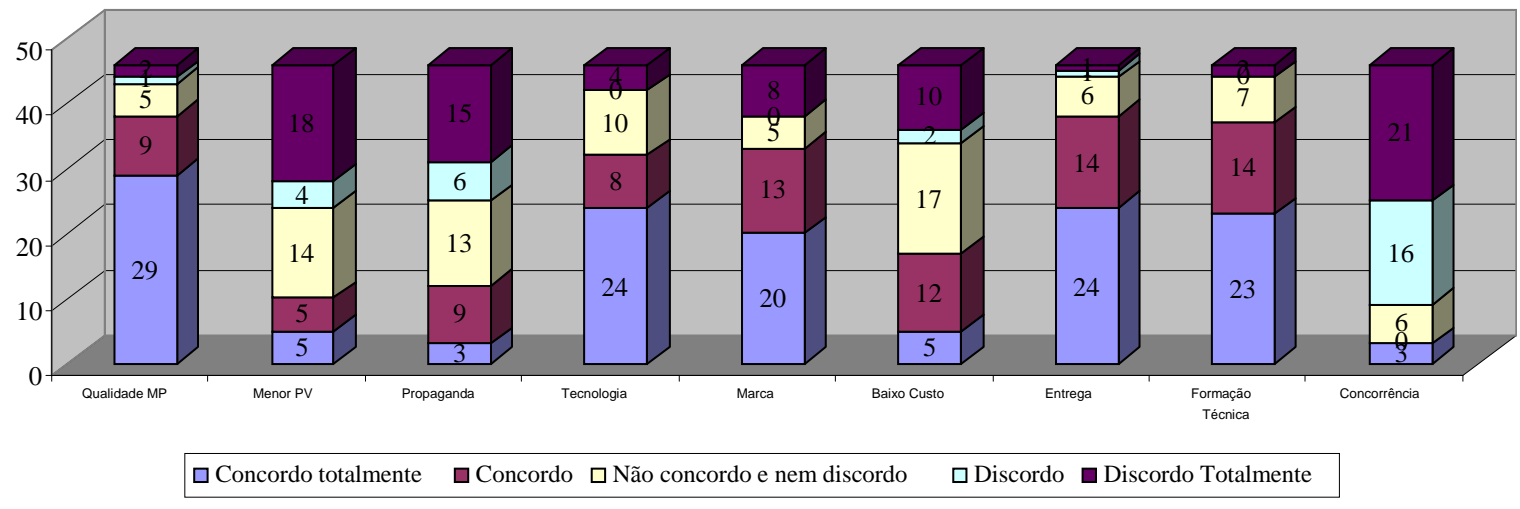

Fonte: Os autores (2012)

A pesquisa revela, para as empresas que participaram da sondagem, que a qualidade da matéria prima, tecnologia, marca definida, prazo de entrega e a formação técnica dos colaboradores é critérios que vão definir a venda de um produto. Enquanto, que fatores como preço de venda, propaganda, nível de concorrência são, para 18 empresas, fatores considerados irrelevantes no fechamento de um pedido.

Finalmente, para o último grupo de questões, o desdobramento dos planos traçados pelas organizações em ações obedecem a determinados padrões. O modelo mais adotado pelas organizações é o 'plano de negócios', indicado por 32\% das empresas. Percebe-se que muitas empresas encontram-se em um nível de maturidade básico em relação às práticas de planejamento, pois $26 \%$ das empresas apontam que não possuem um modelo formal a ser seguido. A formalização de um 'planejamento estratégico' é realizada por $22 \%$ das empresas estudadas, enquanto que $20 \%$ adotam modelos baseados na disciplina da qualidade, como o 'desdobramento pelas diretrizes'.

Especificamente para a gestão da produção, procurou-se identificar o aspecto dominante na gestão do sistema produtivo. O resultado do levantamento realizado aponta que $44 \%$ das empresas pesquisadas consideram a 'integração' como o aspecto mais relevante na gestão dos sistemas de planejamento e controle, ou seja, os sistemas de informação exercem um papel importante na gestão da produção. Num segundo plano, com 39\% de citações, aparecem os modelos tradicionais de planejamento, baseados nos desdobramento de objetivos, metas e indicadores. Finalmente, os modelos baseados nas técnicas de gestão da qualidade respondem por $4 \%$ das empresas. Deve-se destacar que $13 \%$ das empresas declaram não possuir um sistema formal de planejamento e controle da produção.

Para completar o quadro que se queria construir com a sondagem, foram identificadas as metodologias, processos e técnicas mais dotados pelas empresas estudadas. O Gráfico 9 apresenta uma síntese de tal levantamento. 
Figura 9 - Metodologias, processos e técnicas adotadas

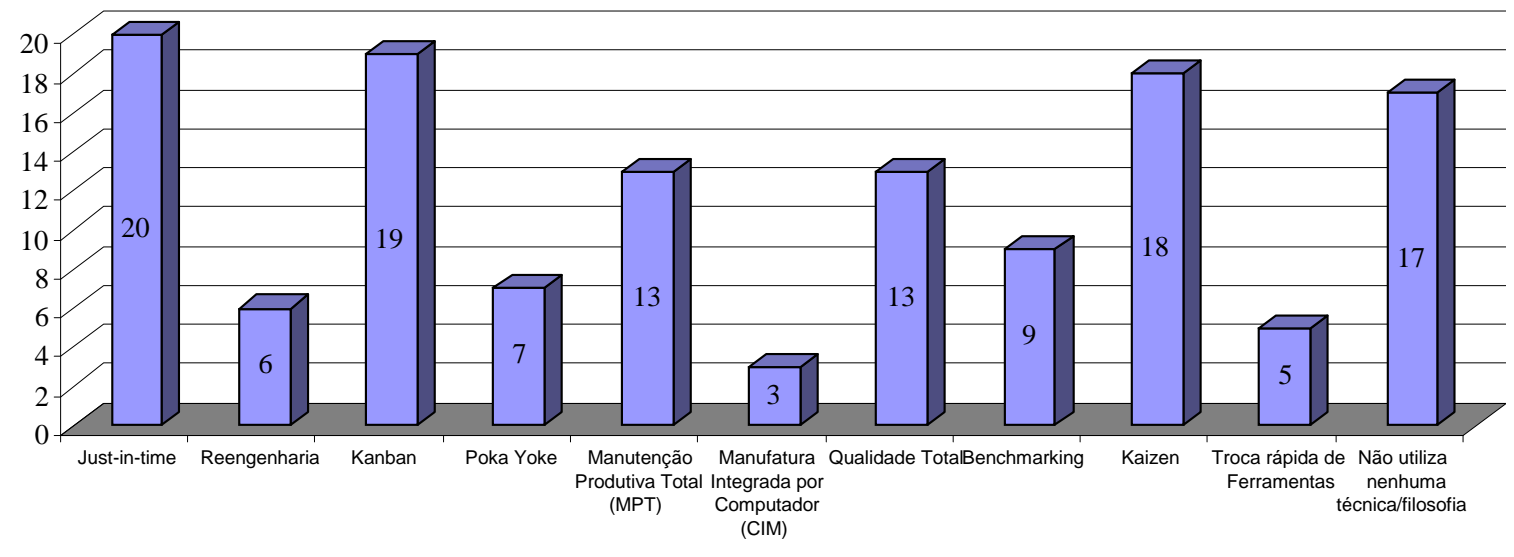

Fonte: Os autores (2012)

A pesquisa demonstra que o Just-in-time, Kanban e Kaizen são muito utilizados pelas empresas pesquisadas. A natureza do processo produtivo e o setor de atuação de tais empresas justificam este alto grau de utilização.

\subsection{Da síntese da pesquisa}

Fundamentando-se na revisão teórico-conceitual e na sondagem realizadas, verifica-se que o inter-relacionamento entre modelos, metodologias, processos e técnicas permite que se aplique um agrupamento a tais elementos. Segundo Backer (1995), classificar ou agrupar objetos em categorias é atividade bastante comum e vem sendo intensificada devido ao número elevado de informações que estão disponíveis atualmente.

Para realizar essa tarefa, emprega-se um mecanismo denominado análise de cluster ou 'clusterização'. De acordo com Jain e Dubes (1988), a 'clusterização' é uma técnica que utiliza o aprendizado não supervisionado ou auto-organizável. Basicamente, a previsão será feita através da representação interna, montada pelo sistema, utilizando um conjunto de dados de entrada, para os quais deverá ser gerada uma listagem com características de cada grupo estudado, selecionando as palavras coincidentes. Através da releitura do quadro, o leitor tem a mesma conclusão proposta pelo autor.

A 'clusterização' dos grupos é demonstrada no Quadro 1, dentro de um enfoque mais qualitativo e fundamentando-se no conteúdo das respostas e relações identificadas.

Quadro 1 - Representações e características

\begin{tabular}{|l|l|l|}
\hline ABORDAGEM & \multicolumn{1}{|c|}{ REPRESENTAÇÕES } & \multicolumn{1}{c|}{ CARACTERÍSTICAS } \\
\hline Business Brain & $\begin{array}{l}\text { O B2 é uma técnica de planejamento e } \\
\text { controle e funciona como um } \\
\text { entregador de informações para o o } \\
\text { gestor. }\end{array}$ & $\begin{array}{l}\text { O processo de planejar é todo integrado já que se } \\
\text { utiliza de displays atualizados on line, provendo } \\
\text { informações claras e confiáveis no momento certo. }\end{array}$ \\
\hline $\begin{array}{l}\text { Tecnologia da } \\
\text { Produção Otimizada }\end{array}$ & $\begin{array}{l}\text { Técnica baseada no uso de software } \\
\text { que visa o controle dos gargalos da }\end{array}$ & $\begin{array}{l}\text { A integracão é a principal característica desta } \\
\text { abordagem que tenta controlar a produtividade já }\end{array}$ \\
\hline
\end{tabular}




\begin{tabular}{|c|c|c|}
\hline & produção. & $\begin{array}{l}\text { que esta faz com que a organização se aproxime } \\
\text { de sua meta. }\end{array}$ \\
\hline $\begin{array}{l}\text { Material } \\
\text { Requirements } \\
\text { Planning - MRP }\end{array}$ & $\begin{array}{l}\text { Considerada uma metodologia de } \\
\text { planejamento e controle, o MRP é } \\
\text { visto com um plano global da } \\
\text { organização avaliando questões } \\
\text { financeiras e de engenharia. }\end{array}$ & $\begin{array}{l}\text { Integrado com as diversas áreas, assim é o } \\
\text { planejamento e controle pelo MRP. O } \\
\text { planejamento dos negócios, vendas, operações, } \\
\text { produção e necessidade de materiais são todos } \\
\text { integrados e coordenados entre si. }\end{array}$ \\
\hline Just in Time - JIT & $\begin{array}{l}\text { É mais do que uma simples técnica, é } \\
\text { uma filosofia que inclui a gestão de } \\
\text { materiais, qualidade, organização } \\
\text { física e administrativa. }\end{array}$ & $\begin{array}{l}\text { A gestão da qualidade total está presente no Just } \\
\text { in Time que enfatiza a estratégia de qualidade } \\
\text { como um diferencial competitivo. }\end{array}$ \\
\hline $\begin{array}{l}\text { Cartas Adaptativas } \\
\text { de Controle }\end{array}$ & $\begin{array}{l}\text { Técnica de controle estatístico de } \\
\text { operacionalização simples e eficaz no } \\
\text { monitoramento do desempenho da } \\
\text { manufatura. }\end{array}$ & $\begin{array}{l}\text { Baseadas nos conceitos de qualidade, o controle } \\
\text { estatístico monitora a variabilidade do processo, } \\
\text { distinguindo causas comuns (inofensivas ao } \\
\text { processo) das causas especiais que devem ser } \\
\text { corrigidas para que o processo permaneça no } \\
\text { padrão de qualidade. }\end{array}$ \\
\hline $\begin{array}{l}\text { Tecnologia da } \\
\text { Informação }\end{array}$ & 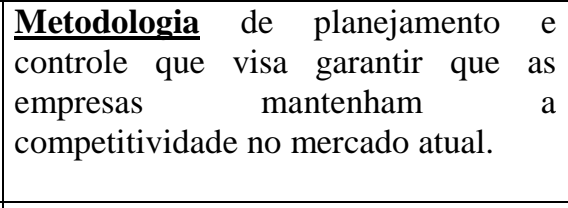 & $\begin{array}{l}\text { Como existe uma integração efetiva com as } \\
\text { diferentes áreas, deve-se tomar cuidado com a } \\
\text { implantação na organização, pois os resultados de } \\
\text { controle são analisados simultaneamente à sua } \\
\text { ocorrência. }\end{array}$ \\
\hline $\begin{array}{l}\text { Enterprise Resource } \\
\text { Planning - ERP }\end{array}$ & $\begin{array}{l}\text { Considerado uma metodologia devido } \\
\text { a sua complexidade na organização, o } \\
\text { ERP é focado nas áreas de negócios, } \\
\text { legislação e tecnologia. }\end{array}$ & $\begin{array}{l}\text { A integracão é presente nesta metodologia pois } \\
\text { ele é composto por módulos de uma base central. } \\
\text { Os dados são armazenados e demonstrados em } \\
\text { forma de desempenho. }\end{array}$ \\
\hline Business Plan & $\begin{array}{l}\text { Modelo dinâmico e interativo de } \\
\text { planejamento e controle que determina } \\
\text { objetivos, políticas e estratégias da } \\
\text { organização. }\end{array}$ & $\begin{array}{l}\text { As diretrizes estratégicas traçadas devem ser } \\
\text { desdobradas para as diversas áreas afins, } \\
\text { implementando um painel de metas para o } \\
\text { acompanhamento do planejado. }\end{array}$ \\
\hline $\begin{array}{l}\text { Desdobramento } \\
\text { pelas Diretrizes }\end{array}$ & $\begin{array}{l}\text { Modelo que transforma a estratégia da } \\
\text { organização em realidade através do } \\
\text { plano de ação. }\end{array}$ & $\begin{array}{l}\text { O desdobramento da diretriz significa dividi-la } \\
\text { em várias sob a responsabilidade de outras } \\
\text { pessoas, assim, num relacionamento meio-fim, } \\
\text { quando esta diretriz for atingida estará ajudando a } \\
\text { garantir o cumprimento da diretriz original. }\end{array}$ \\
\hline $\begin{array}{l}\text { Activity Based } \\
\text { Costing - ABC }\end{array}$ & $\begin{array}{l}\text { Metodologia que determina as } \\
\text { atividades que consomem os recursos } \\
\text { da empresa, agregando para o setor } \\
\text { correspondente. }\end{array}$ & $\begin{array}{l}\text { Baseado no desdobramento, a gestão fulcrada nas } \\
\text { atividades fornece informações que ajudam a fazer } \\
\text { a pergunta correta para o momento e respondê-la } \\
\text { de forma coerente. }\end{array}$ \\
\hline $\begin{array}{l}\text { Balanced Scorecard } \\
\text { - BSC }\end{array}$ & $\begin{array}{l}\text { Modelo que pode ser aplicado a } \\
\text { qualquer tipo de organização desde } \\
\text { que as pessoas e o processo estejam } \\
\text { alinhados com a estratégia. }\end{array}$ & $\begin{array}{l}\text { Tendo como alicerce as quatro perspectivas } \\
\text { (processos, aprendizado, financeira e cliente) o } \\
\text { desdobramento da estratégia é essencial para o } \\
\text { atendimento da principal meta, ou seja, gerar } \\
\text { lucro. }\end{array}$ \\
\hline $\begin{array}{l}\text { Planejamento e } \\
\text { Controle da } \\
\text { Produção - PCP }\end{array}$ & $\begin{array}{l}\text { O PCP é um processo ligado } \\
\text { diretamente à função produção, sendo } \\
\text { que esta é central para as organizações } \\
\text { porque é ela quem produz os bens e } \\
\text { serviços. }\end{array}$ & $\begin{array}{l}\text { Considerado um departamento de apoio à } \\
\text { produção, dentro da gerência industrial, o } \\
\text { desdobramento é presente na estratégia visto que } \\
\text { o PCP é estabelecido para atender as expectativas } \\
\text { de nível estratégico, tático e operacional. }\end{array}$ \\
\hline $\begin{array}{l}\text { Quality Function } \\
\text { Deployment - QFD }\end{array}$ & $\begin{array}{l}\text { Técnica que consiste em capturar as } \\
\text { necessidades do cliente e definir como } \\
\text { elas podem ser atendidas pelo produto. }\end{array}$ & $\begin{array}{l}\text { Vindo dos objetivos da qualidade, o QFD } \\
\text { investiga o produto, levando em consideração a } \\
\text { qualidade exigida e não a potencialidade da } \\
\text { engenharia. }\end{array}$ \\
\hline $\begin{array}{l}\text { Failure Models } \\
\text { Effects Analysis - } \\
\text { FMEA }\end{array}$ & $\begin{array}{l}\text { O desdobramento do produto é uma } \\
\text { técnica que buscará detectar as } \\
\text { possíveis falhas do produto antes da } \\
\text { produção. }\end{array}$ & $\begin{array}{l}\text { O gerenciamento de risco, identificando falhas e } \\
\text { causas, está diretamente ligados à qualidade do } \\
\text { produto, pois tentará eliminar a futura insatisfação } \\
\text { do cliente. }\end{array}$ \\
\hline $\begin{array}{l}\text { Total Quality } \\
\text { Management- } \\
\text { TQM }\end{array}$ & 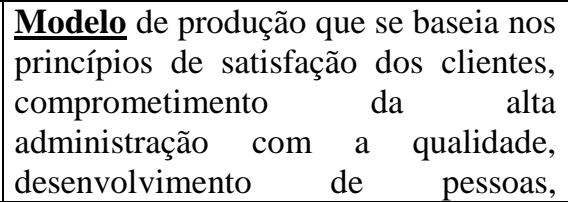 & $\begin{array}{l}\text { A busca pela qualidade total é a meta que deve } \\
\text { ser alcançada por todos na organização, quando } \\
\text { trabalha com o TQM, sendo imprescindível para o } \\
\text { planejamento e controle dos processos produtivos. }\end{array}$ \\
\hline
\end{tabular}




\begin{tabular}{|c|c|c|}
\hline & $\begin{array}{l}\text { padronização de informações e não } \\
\text { aceitação do erro. }\end{array}$ & \\
\hline $\begin{array}{l}\text { Sistema Integrado } \\
\text { de Gestão }\end{array}$ & $\begin{array}{l}\text { O sistema integrado de gestão é uma } \\
\text { combinação de certificações como } \\
\text { ISO } 9000,14000 \text { e } 18001 \text {, visando o } \\
\text { processo operacional. }\end{array}$ & $\begin{array}{l}\text { Com raízes na administração da qualidade, um } \\
\text { bom sistema poderá garantir a competitividade na } \\
\text { organização, pois terá procedimentos que vão } \\
\text { garantir a conquista dos objetivos traçados. }\end{array}$ \\
\hline $\begin{array}{l}\text { Prêmios de } \\
\text { Qualidade }\end{array}$ & $\begin{array}{l}\text { Modelos de gestão que buscam a } \\
\text { excelência, desdobrando sua gestão } \\
\text { em um relatório que será avaliado por } \\
\text { uma comissão, visando a premiação } \\
\text { pelas melhores práticas. }\end{array}$ & $\begin{array}{l}\text { A avaliação é baseada em critérios de excelência } \\
\text { do desempenho, em que a qualidade é o fator } \\
\text { determinante para um bom resultado. }\end{array}$ \\
\hline Lean Manufacturing & $\begin{array}{l}\text { Modelo que combina novas técnicas } \\
\text { gerenciais com máquinas cada vez } \\
\text { mais sofisticadas para produzir mais } \\
\text { com menos recursos. }\end{array}$ & $\begin{array}{l}\text { A produção enxuta pode ser considerada um } \\
\text { conjunto de medidas e métodos que trazem } \\
\text { benefícios para a empresa como um todo, } \\
\text { cuidando sempre com a garantia da qualidade do } \\
\text { produto. }\end{array}$ \\
\hline Seis Sigma & $\begin{array}{l}\text { Técnica que liga idéias, tendências e } \\
\text { ferramentas, tornando o cliente a } \\
\text { prioridade principal da organização. }\end{array}$ & $\begin{array}{l}\text { O nível Seis Sigma é conquistado quando se tem } \\
\text { excelência de qualidade em todo o sistema } \\
\text { logístico com um nível desprezível de falhas. }\end{array}$ \\
\hline
\end{tabular}

Fonte: Os autores (2012)

Uma análise de agrupamento de natureza 'quantitativa' e multivariada foi realizada visando testar os grupos formados no Quadro 1, ou seja, os grupos: 'Desdobramento', 'Qualidade' e 'Integração'.

Os questionários foram tabulados de acordo com o tipo de cada questão. Nas questões em que a resposta variava entre "muito utilizado", atribuiu-se o número 5, o número 4 a "utilizado", e assim respectivamente até o número 1, correspondente a "não conhecemos". Os mesmos valores foram atribuídos ao nível de dependência e de controle de cada ferramenta, sendo o número 5 para o mais elevado e 1 para o menor controle ou dependência. As questões 2.1, 2.2, 3.2, 3.5, 4.5 estão inclusas nesta situação. Para a questão 5.3 em que a resposta se baseia no uso ou não de cada ferramenta, atribui-se o valor 5 para a utilização e 1 para o seu desconhecimento. As demais questões não foram utilizadas, por se tratar de questões fechadas.

Para a análise dos clusters utilizou-se o software Minitab. O dendrograma mais adequado foi gerado usando o método 'Complete'. O critério de agrupamento pelo método Complete se baseia na distância máxima. É chamado assim porque todos os objetos em um agrupamento são conectados entre si limitados por uma distância máxima que define uma similaridade mínima (HAIR et al, 2006). O dendrograma resultante deste método é apresentado na Figura 1. 
Figura 10 - Dendrograma utilizando o método Complete

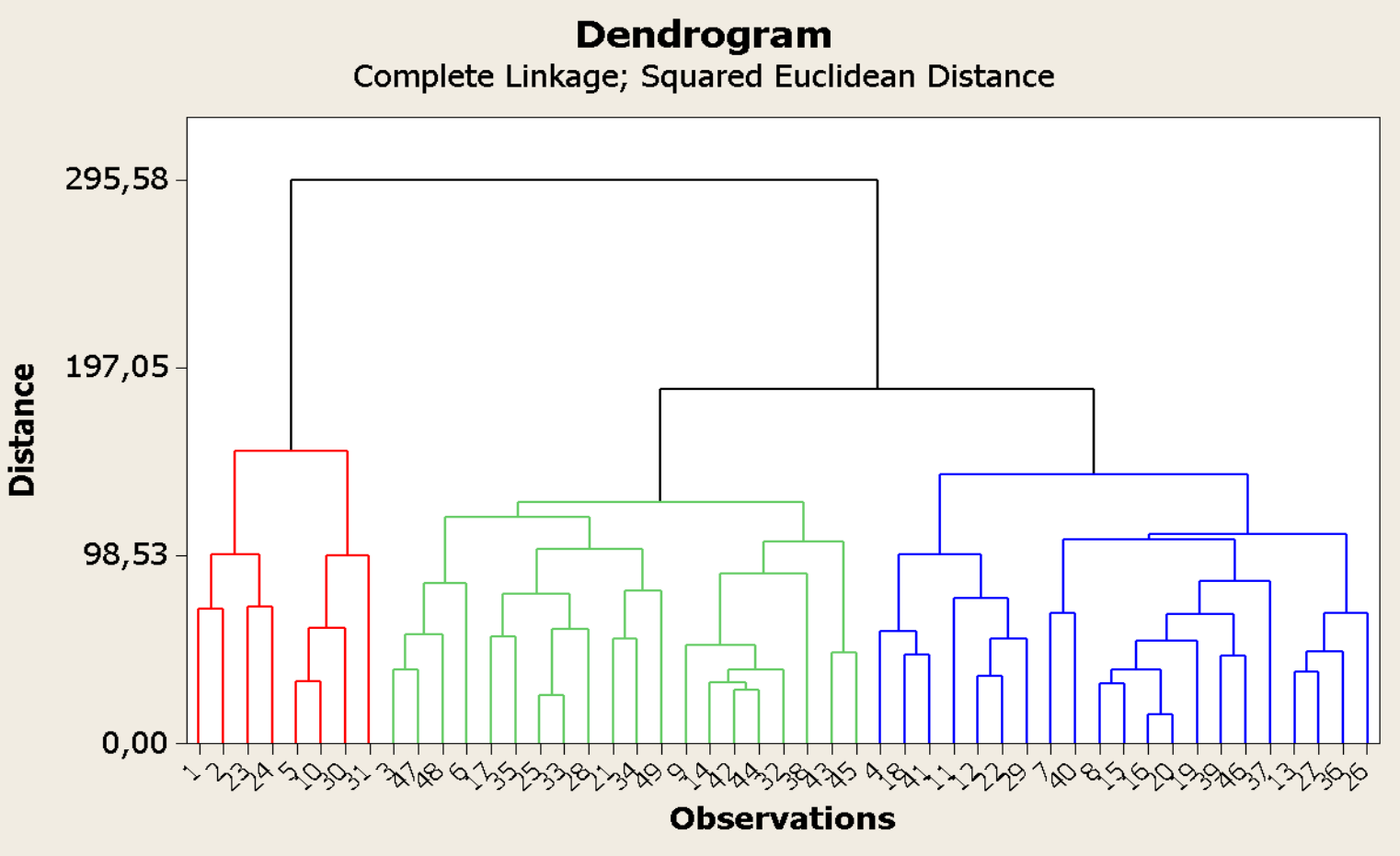

Fonte: Os autores (2012)

Através do dendrograma pode-se verificar a formação de três agrupamentos ou clusters. O primeiro sendo formado por 8 observações, ou seja, por oito empresas. O segundo agrupamento é formado por 20 e o terceiro por 21 observações. Depois de selecionado o método Complete, as observações de cada cluster foram analisadas e comparadas. A análise de cada observação permitiu verificar as ferramentas utilizadas por cada grupo.

É possível para os grupos formados, verificar os modelos, processos ou técnicas que se inter-relacionam entre si, via identificação dos quesitos envolvidos. O primeiro agrupamento possui características marcantes do grupo 'Desdobramento', enquanto que o segundo e terceiro agrupamentos correspondem a 'Qualidade' e 'Integração' respectivamente. Nenhum dos três agrupamentos constitui um grupo que poderia ser chamado de 'puro', pois os mesmos combinam os modelos básicos, customizando-os ao ambiente estratégico e operacional que é específico de cada empresa. Resta saber se há um conjunto finito de combinações a serem contingencialmente escolhidos para orientar o projeto dos sistemas de planejamento e controle da produção.

Fundamentando-se no Quadro 1 e na Figura 1, podem ser exploradas as representações e as características de cada grupo de lógica identificada. Percebe-se que há grandes grupos de lógicas de planejamento e controle. O agrupamento é feito por palavras-chave, o que contribui para a direta identificação dos grupos.

Uma síntese da pesquisa pode ser construída através de um framework de referência. Tal construção é 'populada' pelos elementos identificados na pesquisa realizada. O framework 
apresentado na Figura 2 ilustra a dinâmica do planejamento e controle da produção, identificando causalidades, os laços de realimentação e delimitando o escopo de atuação do sistema.

A Figura 2 sugere que se possam combinar diferentes abordagens, metodologias, processos e técnicas, gerando o que se poderia chamar de modelos híbridos. Os grupos de lógica identificados contribuem para a construção de uma classificação para os modelos que a princípio poderiam enquadrar-se nos tipos 'Desdobramento', 'Qualidade' ou 'Integração'.

Figura 11 - Framework de referência

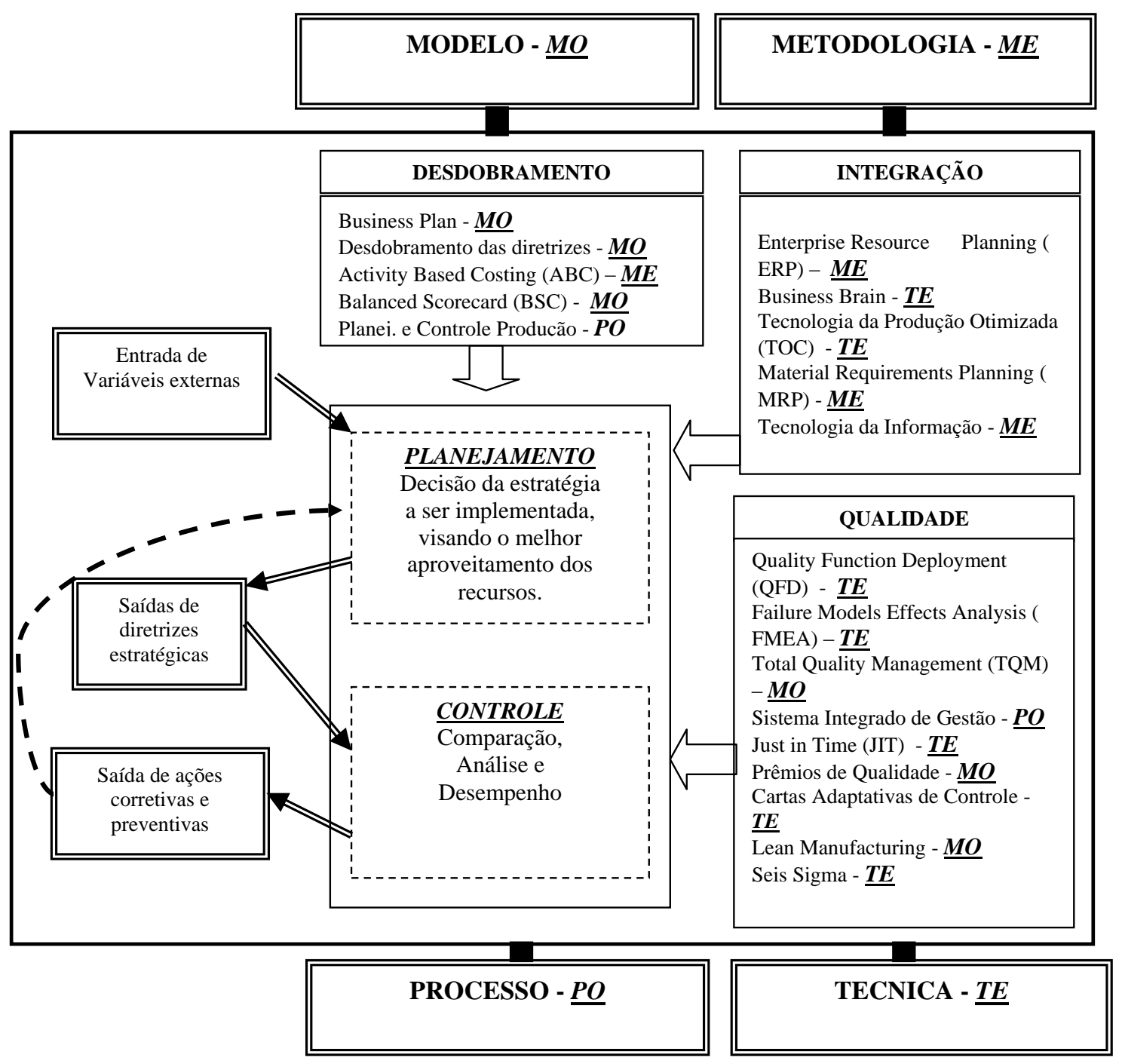

Fonte: Os autores (2012)

A escolha do modelo de gestão é, na realidade, uma decisão de projeto do sistema de gestão da produção ou do sistema de gestão de operações. Este trabalho contribui para esse processo de decisão na medida em que estabelece um referencial teórico para tal discussão. 


\section{Conclusão}

A grande motivação da pesquisa realizada e que orientou o desenvolvimento deste artigo é a necessidade de se saber quais são 'lógicas' ou abordagens de planejamento e controle de operações de produção adotadas pelas empresas. Verificou-se, de maneira exploratória e para um grupo específico de empresas, que os grupos de lógicas fundamentam-se em aspectos relacionados à 'Integração', 'Desdobramento' e 'Qualidade'.

Percebe-se que a abordagem que é caracterizada pela lógica de 'Integração' possui um enfoque tecnológico cuja arquitetura básica é fundamentada em sistemas ERP. Tais sistemas implementam tanto funções gerenciais, como também tratam de aspectos operacionais. O nível de integração entre as diversas áreas ou funções relacionadas ao sistema de operações produtivas define a dinâmica de funcionamento do sistema de planejamento e controle. Quanto maior o nível de integração, maior será a capacidade analítica e de operação em tempo real da gestão das operações produtivas.

No segundo grupo, classificado aqui como 'Desdobramento', contém os elementos clássicos

de planejamento, trabalhando com uma visão hierarquizada das funções, objetivos, metas e indicadores. Tal abordagem caracteriza-se pelos fluxos verticais de informação e pela formalização do escopo de controle. Os métodos dedutivo e analítico marcam a dinâmica de funcionamento deste grupo.

O terceiro grupo, aqui denominado de 'Qualidade', caracteriza-se pelas organizações que se utilizam dos modelos, processos e técnicas de gestão da qualidade para planejar e controlar o sistema de operações produtivas. Este grupo caracteriza a gênese do modelo japonês de gestão da produção, ou seja, uma espécie de grounded theory. O método indutivo e a síntese caracterizam a dinâmica de operação deste grupo.

Dadas as restrições do trabalho em termos de universo de empresas estudadas, da natureza exploratória da pesquisa e da própria técnica de pesquisa, sugere-se ampliar o universo de estudo, bem como conduzir estudos de caso para compreender melhor o projeto, a implementação e o uso dos modelos, metodologias, processos e técnicas para o planejamento e controle de operações.

Uma das contribuições deste estudo foi a de ter feito uma análise do planejamento e controle da produção, contextualizado pela gestão estratégica da produção. Contribui, portanto, para o campo da estratégia de manufatura, ao demonstrar de forma exploratória, as abordagens de Planejamento e Controle, apresentando assim, uma sugestão de classificação em grupos de acordo com a sua natureza. Este estudo, embora seja focado na estratégia de Operações, pode servir de base para outras áreas funcionais da organização e também com o modelo de gestão adotado.

A direção deve conduzir o processo de planejamento e controle, transmitindo a visão, ajudando a definir objetivos e metas, estando sempre presente, acompanhando resultados e 
resolvendo problemas, pois, escolhidas as estratégias, segue-se para a elaboração dos planos de implementação. Os resultados obtidos e os novos problemas devem contribuir para a evolução do modelo organizacional, criando-se as condições necessárias para o desenvolvimento dos processos de melhoria contínua, com amplo envolvimento das pessoas, na constante busca de realização da missão e visão empresariais.

\begin{abstract}
Nowadays, companies are bounded by a complex and dynamic environment and for attending their demands it is required to develop a flexible system for managing their operations, as well to accomplish changes in their business environment. This article intends to identify operations planning and control approach for integrating models, methodologies, processes and techniques for manufacturing and services companies' operations planning and control. The developed research is exploratory by nature and uses online questionnaires for surveying and specific enterprise group. The research could be classified as an electronic exploratory survey. The studied companies are associated to Curitiba's Metal-Mechanic Company Union (SINDIMETAL) and they constitute 180 organizations belonging to the metal-mechanic industry. The research results identified three groups for approaching companies' operations planning and control systems, named as: 'Deployment', 'Quality' and 'Integration'.
\end{abstract}

Key-words: management models; planning and control; production management; operations strategic management.

\title{
Referências
}

ALLIPRANDINI, D.H.; TOLEDO, J.C. Sistemas de gestão da qualidade. São Carlos: GREDEQ, 1993.

ANDERSEN, H.V.; LAWRIE, G.; SAVIC, N. Effective quality management through third-generation balanced scorecard. International Journal of Productivity and Performance Management, v. 53, n. 7, p. 634-645, 2004.

cross ref

ATKINSON, A; KAPLAN, R.S.; YOUNG, S.M. Management Accounting. 5 ed. Upper Saddle River: Prentice-Hall, 2007.

AVISON, D.E.; FITZGERALD, G. - Information Systems Development: Methodologies, Techniques and Tools Blackwell Scientific Publications., 1997.

BACKER, E. Computer assisted reasoning in cluster analysis. New York: Prentice-Hall, 1995.

BARBER, K.D.; DEWHURST, F.W.; BURNS, R.L.D.H.; ROGERS, J.B.B. Business-process modelling and simulation for manufacturing management: a practical way forward. Business Process Management Journal, v. 9, n. 4, p. $527-$ 542, 2003.

cross ref

BISCHAK, D.P.; TRIETSCH D. The rate of false signals in X-bar control charts with estimated limits. Journal of Quality Technology, v. 39, n. 1, p. 54-65, 2007.

BOU-LLUSAR, J.C.; ESCRIG-TENA, A.B.; ROCA-PUIG, V.; BELTRÁN-MARTÍN, I. An empirical assessment of the EFQM Excellence Model: evaluation as a TQM framework relative to the MBNQA Model. Journal of Operations Management, v.27, n.1, p.1-22, 2009.

cross ref

BROWN, S. Manufacturing strategy, manufacturing seniority and plant performance in quality. International Journal 
of Operations \& Production Management, v. 18, n. 6, p. 565-587, 1998.

cross ref

CAMPOS, V.F. Gerenciamento pelas diretrizes. Belo Horizonte: Bloch/Fundação Christiano Ottoni, 1996.

CARNEVALLI, J.A.; MIGUEL, P.C. Review, analysis and classification of the literature on QFD: types of research, difficulties and benefits. International Journal of Production Economics, v. 114, n. 2, p. 737-754, 2008.

cross ref

CAUCHICK MIGUEL, P.A.; MORINI, C.; PIRES, S.R.I. An application case of the Brazilian National Quality Award. The TQM Magazine, v.16, n.3, p.186-193, 2004.

cross ref

CHAKRAVORTY, S.S. Six Sigma programs: An implementation model. International Journal of Production Economics, v. 119, n. 1, p. 1-16, 2009.

cross ref

CHAVAN, M. The balanced scorecard: a new challenge. Journal of Management Development, v. 28, n. 5, p. 393406, 2009.

cross ref

COGAN, S. Activity-based costing (ABC): a poderosa estratégia empresarial. São Paulo: Pioneira, 1994.

CORONADO, A.E.M.; SARHADI, M.; MILLAR, C. Defining a framework for information systems requirements for agile manufacturing. International Journal of Production Economics, v. 75, n. 1/2, p. 57-68, 2002.

cross ref

CORRÊA, H.L.; CAON, M.; GIANESI, I.G.N. Planejamento, programação e controle da produção: MRPII/ERP. São Paulo: Atlas, 2001.

DA SILVA, J.G.; TADASHI, O.; KIKUO, N. Looking through and beyond the TQM horizon: lessons learned from world-class companies. The TQM Magazine, v.17, n.1, p.67-84, 2005.

cross ref

DIETER, G.E. Engineering design. New York: McGraw-Hill, 1991.

DOUMEINGTS, G.; CHEN, D.; MARCOTTE, F. Concepts, models and methods for the design of production management systems. Computers in Industry, v. 19, n. 1, p. 89-111, 1992.

cross ref

DRIVER, M. Activity-based costing: a tool for adaptive and generative organizational learning? The Learning Organization, v.8, n.3, p.94-105, 2001.

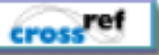

FERNANDES, F.C.F.; GODINHO FILHO, M.; BONNEY, M. A proposal for integrating production control and quality control. Industrial Management \& Data Systems, v. 109, n. 5, p. 683-797, 2009.

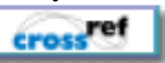

FLYNN, B.B.; SALADIN, B. Relevance of Baldrige constructs in an international context: a study of national culture. Journal of Operations Management, v.24, n.5, p.583-603, 2006.

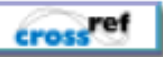

FLYNN, B.B.; SCHROEDER, R.G., FLYNN, E.J.; SAKAKIBARA, S.; BATES, K.A. World-class manufacturing project: overview and selected results. International Journal of Operations \& Production Management, v.17, n.7, p. 671-685, 1997.

\section{cross ref}


FORZA, C. Quality information systems and quality management: a reference model and associated measures for empirical research. Industrial Management \& Data Systems, v. 95, n. 2, p. 6-14, 1995.

cross ref

GALliANO, A.G.O. Método científico: teoria e prática. SP:Habra, 1979.

GARCIA-CEBRIAN, L.I.; LOPEZ-VINEGLA, A. The use of the scorecard in the management of productionoperations. Industrial Management \& Data Systems, v. 102, n. 1, p. 39-46, 2002.

cross ref

GLAUTIER, M.W.E.; UNDERDOWN, B. Accounting theory and practice. London: Pitman, 1991.

HAIR, J.F.; ANDERSON, R.E.; TATHAM, R.L.; BLACK, W.C. Análise multivariada de dados. 5. ed. Porto Alegre: Bookman, 2006.

HAMILTON, M.B. Online survey response rates and times: background and guidance for industry. Cambridge: Tercent, 2003.

HELO, P.; ANUSSORNNITISARN, P.; PHUSAVAT, K. Expectation and reality in ERP implementation: consultant and solution provider perspective. Industrial Management \& Data Systems, v. 108, n. 8, p. 1045-1059, 2008.

cross ref

HERATH, S.K. A framework for management control research. Journal of Management Development, v. 26, n. 9, p. 895-915, 2007.

cross ref

HERZOG, N.V.; TONCHIA, S.; POLAJNAR, A. Linkages between manufacturing strategy, benchmarking, performance measurement and business process reengineering. Computers \& Industrial Engineering, v. 57, n. 3, p. 963-975, 2009.

cross ref

HILL, T. Manufacturing strategy: text and cases. Boston: Irwin, 1989.

HVOLBY, H-H.; TRIENEKENS, J.H. Challenges in business systems integration. Computers in Industry, v. 61, n. 9, p. $808-812,2010$.

cross ref

HUARNG, F.; CHEN, Y.T. Relationships of TQM philosophy, methods and performance: a survey in Taiwan. Industrial Management \& Data Systems, v. 102, n. 4, p. 226-234, 2002.

cross ref

JAIN, A.K.; DUBES, R.C. Algorithms for clustering data. Englewood Cliffs: Prentice-Hall, 1988.

JONSSON, P.; KJELLSDOTTER, L.; RUDBERG, M. Applying advanced planning systems for supply chain planning: three case studies. International Journal of Physical Distribution \& Logistics Management, v. 37, n. 10, 816-834, 2007.

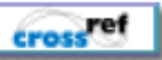

JONSSON, P.; MATTSSON, S.A. The implications of fit between planning environments and manufacturing planning and control methods. International Journal of Operations \& Production Management, v. 23, n. 8, p. 872-900, 2003.

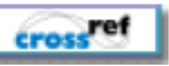

KAKOURIS, A. P.; POLYCHRONOPOULOS, G. Enterprise Resource Planning (ERP) System: an effective tool for production management. Management Research News, v.28, n.6, p.66-78, 2005.

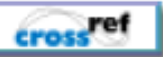


KAPLAN, R.S.; COOPER, R. Cost and effect: using integrated cost systems to drive profitability and performance. Boston: Harvard Business School Press, 1997.

KAPLAN, R.S.; NORTON, D.P. The balanced scorecard - measures that drive performance. Harvard Business Review, v.70, n.1, p.71-79, 1992.

KASZUBSKI, M.A.; EBBEN, S. Using activity-based costing to implement behavioural cost initiatives successfully. Journal of Facilities Management, v.3, n.2, p.184-192, 2004.

cross ref

KELLER, A.Z.; KAZAZI, A. ?Just-in-Time? manufacturing systems: a literature review. Industrial Management \& Data Systems, v. 93, n. 7, p. 2-32, 1993.

cross ref

KELLER; G.; TEUFEL, T. SAP R/3 Process-oriented implementation. Harlow: Addison-Wesley, 1998.

KESSLER, R.M. A implantação do Seis Sigma em organização: motivações de escolha e resultados. Dissertação (mestrado) - Universidade Federal do Rio Grande do Sul, 2004.

KONTZ,H; O'DONNELL, C. Administração: fundamentos da teoria e da ciência. 15 ed. São Paulo: Pioneira, 1995.

KOVÁCS, G.L.; PAGANELLI, P. A planning and management infrastructure for large, complex, distributed projects beyond ERP and SCM. Computers in Industry, v. 51, n. 2, p. 165-183, 2003.

cross ref

KULL, T.J.; WACKER, J.G. Quality management effectiveness in Asia: The influence of culture. Journal of Operations Management, v. 28, n. 3, p. 223-239, 2010.

cross ref

KULVATUNYOU, B.; WYSK, R.A. A functional approach to enterprise-based engineering integration. Journal of Manufacturing Systems, v. 19, n. 3, p. 156-171, 2000.

cross ref

KUMAR, S.; MEADE, D. Has MRP run its course? a review of contemporary developments in planning systems. Industrial Management \& Data Systems, v. 102, n. 8, p. 453-462, 2002.

cross ref

LIN, C.H.; HWANG, S.L.; WANG, E.M.Y A reappraisal on advanced planning and scheduling systems. Industrial Management \& Data Systems, v. 107, n. 8, p. 1212-1226, 2007.

cross ref

MACHLINE, C.; MOTTA, I.S.; SCHOEPS, W.; WEIL, K.E. Manual de administração da produção. 7 ed. Rio de janeiro: Fundação Getúlio Vargas, 1984.

MARTÍNEZ-COSTA, M.; CHOI, T.Y.; MARTÍNEZ-GARCÍA, J.A.; MARTÍNEZ-LORENTE, A.R. ISO 9000/1994, ISO 9001/2000 and TQM: the performance debate revisited. Journal of Operations Management, v. 27, n. 6, p. 495$511,2009$.

cross ref

MARTÍNEZ-OLVERA, C. Benefits of using hybrid business models within a supply chain. International Journal of Production Economics, v. 120, n. 2, p. 501-511, 2009.

cross ref

MATOOK, S.; INDULSKA, M. Improving the quality of process reference models: A quality function deploymentbased approach. Decision Support Systems, v. 47, n. 1, p. 60-71, 2009.

cross ref 
MELCHER, A.J.; KHOUJA, M.; BOOTH, D.E. Toward a production classification system. Business Process Management Journal, v. 8, n. 1, p. 53-79, 2002.

cross ref

MISTRY, J.J. Origins of profitability through JIT processes in the supply chain. Industrial Management \& Data Systems, v.105, n.6, p. 752-768, 2005.

cross ${ }^{\text {ref }}$

MULA, J.; POLER, R.; GARCÍA-SABATER, J.P.; LARIO, F.C. Models for production planning under uncertainty: a review. International Journal of Production Economics, v. 103, n. 1, p. 271-285, 2006.

cross ref

NAKAGAWA, M. ABC - $\quad$ custeio Baseado em atividades. $\quad$ São $\quad$ Paulo: Atlas, 1995.

OLIVEIRA, D.P.R. Estratégia empresarial e vantagem competitiva: como estabelecer e implementar e avaliar. São Paulo: Atlas, 2001.

NIETO, M.; ARIAS, D.; MINGUELA, B.; RODRIGUEZ, A. The evolution of operations management contents: an analysis of the most relevant textbooks. Industrial Management \& Data Systems, v. 99, n. 8, p. 345-352, 1999.

cross ref

NO, J.J.; KLEINER, B.H. How to implement activity-based costing, Logistics Information Management, v.10, n.2, p.68-72, 1997.

cross ref

OHNO, T. O sistema Toyota de produção além da produção em larga escala. Porto Alegre: Bookman, 1997.

ONWUBOLU, G.C.; MHLANGA, S. POM: a highly visual production and operations management environment. Industrial Management \& Data Systems, v. 97, n. 3, p. 99-113, 1997.

cross ref

PALANISAMY, R. Strategic information systems planning model for building flexibility and success. Industrial Management \& Data Systems, v. 105, n. 1, p. 63-81, 2005.

cross ref

PEREIRA, E.A.R.; PINHEIRO DE LIMA, E.; GOUVÊA DA COSTA, S.E. O estudo das diferentes lógicas de planejamento e controle - uma contribuição para o gerenciamento estratégico de operações. Sistemas \& Gestão, v.3, n.1, p.39-54, 2008.

PILKINGTON, A.; MEREDITH, J. The evolution of the intellectual structure of operations management 1980-2006: a citation/co-citation analysis. Journal of Operations Management, v. 27, n. 3, p. 185-202, 2009.

cross ref

PINHEIRO DE LIMA, E.; GOUVÊA DA COSTA, S.E.; ANGELIS, J.J. Framing operations and performance strategic management system design process. Brazilian Journal of Operations and Production Management, v. 5, n. 1, p. 2345, 2008.

PINHEIRO DE LIMA, E. Uma modelagem organizacional baseada em elementos de natureza comportamental. Florianópolis, 2001. Tese de Doutorado em Engenharia de Produção - UFSC, 2001.

PLATTS, K.W. Strategies for sustainable manufacturing, in International Conference on Industrial Engineering and Operations Management - ICIEOM 2007, Plenary Lecturer, Foz do Iguassu, Brazil, 2007.

RAGHUNATHAN, T.S.; SUBBA RAO, S.; SOLIS, L.E. A comparative study of quality practices: USA, China and India. Industrial Management \& Data Systems, v. 97, n. 5, p. 192-200, 1997.

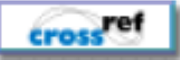

RAMIREZ, R.; MELVILLE, N.; LAWLER, E. Information technology infrastructure, organizational process redesign, and business value: An empirical analysis. Decision Support Systems, v. 49, n. 4, p. 417-429, 2010. 
RENTES, A.F.;VAN AKEN,E.M.; BUTLER, R. An organizational assessment method for transformation efforts. Proceedings of the Portland International Conference on Management of Engineering and Technology, Portland, 1999.

RESENDE, D.A.; ABREU, A.F. Tecnologia da informação aplicada a sistemas de informação empresariais. São Paulo: Atlas, 2000.

RIEZEBOS, J.; KLINGENBERG, W.; HICKS, C. Lean Production and information technology: connection or contradiction? Computers in Industry, v. 60, n. 4, p. 237-247, 2009.

\section{cross ${ }^{\text {ref }}$}

ROTONDARO R. G. et al, Seis Sigma - Estratégia Gerencial para a Melhoria de Processos, Produtos e Serviços. São Paulo, Brasil. Editora Atlas S.A. 2004.

SALERNO, Mario S. Projeto organizacional de produção integrada, flexível e de gestão democrática: processos, grupos e espaços de comunicação - negociação. Tese (Livre-Docência). Departamento de Engenharia de Produção, Escola Politécnica da Universidade de São Paulo. São Paulo, 1998.

SAHLMAN, W.A. How to write a great business plan. Harvard Business Review, v. 75, n. 4, p. 98-108, 1997.

SAMARANAYAKE, P. Business process integration, automation, and optimization in ERP: Integrated approach using enhanced process models. Business Process Management Journal, v.15, n.4, p.504-526, 2009.

$$
\text { cross }
$$

SCHROEDER, R.G.; LINDERMAN, K.; LIEDTKE, C.; CHOO. A.S. Six Sigma: definition and underlying theory. Journal of Operations Management, v. 26, n. 4, p. 536-554, 2008.

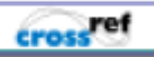

SEMENIK, R. J.; BAMOSSY, G. J. Princípios do marketing: uma perspectiva global. São Paulo: Makron Books, 1995.

SHEEHAN, K. E-mail survey response rates: a review. Journal of Computer-Mediated Communication, v.6, n.2, p.1-20, 2001.

SKINNER, W. Manufacturing - missing link in corporate strategy. Harvard Business Review, v. 47, n. 3, p. 136-145, 1969.

SLACK, N.; CHAMBERS, S.; JOHNSTON, R. Administração da produção. 2 ed. São Paulo: Atlas, 2002.

SMITH, I.; BOYNS, T. British management theory and practice: the impact of Fayol. Management Decision, v. 43, $\mathrm{n}$. 10 , p. $1317-1334,2005$

cross ref

SPRAGUE, R.H.; WATSON, H.J. Decision support for management. Upper Saddle River: Prentice-Hall, 1996. TAN, K.C. A comparative study of 16 national quality awards. The TQM Magazine, v.14, n.3, p.165-171, 2002.

cross ref

TSENG, Y.J.; KAO, Y.W.; HUANG, F.Y. A model for evaluating a design change and the distributed manufacturing operations in a collaborative manufacturing environment. Computers in Industry, v. 59, n. 8, p. 798-807, 2008.

cross ref

VALERIANO, D. L.(1998). Gerência em Projetos, Editora Makron Books, São Paulo, p.16-17, 146-149, $178-189$.

VAN NIEUWENHUYSE, I.; DE BOECK, L.; LAMBRECHT, M.; VANDAELE, N.J. Advanced resource planning as a decision support module for ERP. Computers in Industry, v. 62, n. 1, p. 1-8, 2011.

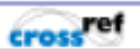

VASCONCELOS FILHO, P.; MACHADO, A.M.V. Planejamento estratégico: formulação, implementação e 
controle. Rio de Janeiro: LTC, 1994.

VERBEETEN, F.H.M.; BOONS, A.N.A.M. Strategic priorities, performance measures and performance: an empirical analysis in Dutch firms. European Management Journal, v. 27, n. 2, p. 113-128, 2009.

cross ref

WARNECKE, H.J., HÜSER, M. Lean production. International Journal of Production Economics, v.41, n.1/2/3, p. 37-43, 1995.

WATSON, K.J.; BLACKSTONE, J.H.; GARDINER, S.C. The evolution of a management philosophy: the theory of constraints. Journal of Operations Management, v. 25, n. 2, p. 387-402, 2007.

cross ref

WOMACK, J. P; JONES, D. T., ROOS, D. A máquina que mudou o mundo. 4. ed. Rio de Janeiro: Campus, 2004.

YAHYA, S; GOH, W.K. The implementation of ISO 9000 quality system, International Journal of Quality \& Reliability Management, v. 18, n. 9, p. 941-966, 2001.

cross ref

YOURDON, Edward, Modern Structured Analysis, Englewood Cliffs (New Jersey), Yourdon Press/ Prentice Hall, 1997.

ZILBOVICIUS, M. Modelos para a produção, produção de modelos: contribuição à análise da gênese, lógica e difusão do modelo japonês. São Paulo: Anna Blume/ FAPESP, 1999.

ZILBOVICIUS, M. Modelos para a produção e produção de modelos. Tese (Doutorado). Departamento de Engenharia de Produção, Escola Politécnica da Universidade de São Paulo. São Paulo, 1997.

\section{APÊNDICE A - Questionário da Sondagem}

Questionário a ser aplicado junto as organizações localizadas em Curitiba e Região Metropolitana com o objetivo de identificação das diferentes abordagens de Planejamento de Controle do sistema de produção.

\section{IDENTIFICAÇÃO DA ORGANIZAÇÃo}

1.1 Razão Social:

1.2 Cidade:

1.3 Ramo industrial e/ou serviços:

1.4 Número de colaboradores:

1.5 Respondente:

1.6 Função do Respondente:

\section{ESTRATÉGIA DE OPERAÇÕES DA EMPRESA}

2.1 Enumere de acordo com que a empresa utiliza-se dos itens abaixo para garantir e controlar a qualidade dos seus produtos e serviços:

$\begin{array}{lllll}\text { [ } 1 \text { Muito Utilizado } & \text { [2 }] & \text { Utilizado } & \text { [ 3 ] } & \text { Pouco Utilizado } \\ \text { [ 4 ] Não é utilizado } & \text { [ 5 ] } & \text { Não conhecemos } & \end{array}$

a) Total Quality Management - TQM
b) ISO $9001: 2000$
c) ISO 14001 - Gestão Ambiental
d) OHSAS 18001 - Saúde Ocupacional e Segurança

$[1][2] \quad[3] \quad[4]$

$[1] \quad[2] \quad[3] \quad[4]$

$[1] \quad[2] \quad[3]$

[1]
3 ] 4

[3] [4
[5]

[5]

[5] 

e) Participação em prêmios de qualidade - PNQ
[1]
[2]
[3]
[4]
[ 5]
f) Quality Function Deployment - QFD
[1]
[2]
[3]
[4]
[5]
g) Failure Models Effects Analysis - FMEA
[1]
[2]
[ 3 ]
[4]
[5]
h) Outras, especificar:

2.2 Enumere de acordo com que a empresa utiliza-se das abordagens abaixo para gerenciar e controlar seu processo produtivo.
[1] Muito Utilizado
[2] Utilizado
[ 3 ] Pouco Utilizado
[ 4 ] Não é utilizado
[ 5 ] Não conhecemos
a) Balanced Scorecard - BSC
$[1]$
[2] [3]
[4]
[ 5 ]
b) Desdobramento pelas diretrizes
[1] [2] [3]
[4]
c) Activity Based Costing - $\mathrm{ABC}$
[1] [2] [3]
[4]
e) Planejamento e Controle da Produção - PCP
[1] [2] [3]
[4]
f) Plano de Negócios
[1] [2] [3] [4
g) Enterprise Resource Planning - ERP
[1] [2] [3]
[4]
[5]
h) Lean Manufacturing - Produção enxuta
[1]
[2]
[3]
[4]
i) Outros: Especificar

\section{QUANTO A ABORDAGEM TECNOLÓGICA DAS AREAS FUNCIONAIS:}

Com relação a Integração da empresa, assinale de acordo com o grau de utilização diária dentro dos processos produtivos .

3.1 A empresa possui um software integrado que controla entradas, saídas e processos integrando as diversas áreas com a produção.

( ) Sim utilizamos o

( ) Não, mas estamos implementando o

( ) Não, cada área utiliza planilhas de Excel para o controle.

( ) Não, a empresa não utiliza softwares para o controle da produção.

3.2 Até que ponto as áreas gerenciais abaixo dependem de softwares para o planejamento e o controle de suas estratégias de operações industriais?

$\begin{array}{lllll} & \text { Alta } & \text { Dependência } & \text { Baixa } & \begin{array}{l}\text { Nenhuma } \\ \text { Dependência }\end{array} \\ \text { Logística de materiais } & \text { Dependência } & \text { Mediana } & 4 \\ \text { Planejamento e controle da produção } & 1 & 2 & 3 & 4 \\ \text { Compras e distribuição } & 1 & 2 & 3 & 4 \\ \text { Desenvolvimento de projetos } & 1 & 2 & 3 & 4 \\ \text { Controle da capacidade produtiva } & 1 & 2 & 3 & 4 \\ \text { Outra } & 1 & 2 & 3 & 4\end{array}$

\footnotetext{
3.4 O gerenciamento da seqüência em que os produtos serão fabricados, obedecendo a forma de produção "puxados" ou "empurrados" utilizado pela organização é feita:
}

( ) Utilizando um software específico desenvolvido pela própria empresa , sem integração com outros sistemas. 
( ) Utilizando um software específico adquirido de uma empresa especializada, sem integração com outros sistemas.

( ) Utilizando um software específico, que é um dos módulos do sistema integrado ERP, o qual foi adquirido de uma empresa especializada

( ) Utilizando um software específico, que é um dos módulos do sistema integrado ERP, o qual foi desenvolvido pela própria empresa

( ) Sem o uso da informática

( ) Outra alternativa. Especificar:

3.5 Enumere de acordo com o grau de controle que você tem para os indicadores abaixo classificando em:

[ 1 ] Controlo on line, no momento que ocorrem;

[2] Controlo diariamente;

[3] Controlo semanalmente;

[4] Controle mensalmente;

[ 5] Não controlo este indicador.

\begin{tabular}{|c|c|c|c|c|c|}
\hline Refugo Interno & {$[1]$} & {$[2]$} & {$[3]$} & {$[4]$} & {$[5]$} \\
\hline Volume Produção horária/diária/mensal & {$[1]$} & {$[2]$} & [3] & [4] & [ 5 ] \\
\hline Acidentes & {$[1]$} & {$[2]$} & [ 3 ] & {$[4]$} & {$[5]$} \\
\hline Produtividade & {$[1]$} & {$[2]$} & {$[3]$} & {$[4]$} & {$[5]$} \\
\hline Custo de Produção & {$[1]$} & {$[2]$} & {$[3]$} & [ 4 ] & {$[5]$} \\
\hline Volume de Vendas & {$[1]$} & {$[2]$} & [ 3 ] & {$[4]$} & {$[5]$} \\
\hline Lucro Operacional & {$[1]$} & {$[2]$} & {$[3]$} & [ 4 ] & {$[5]$} \\
\hline Preço de Venda & {$[1]$} & {$[2]$} & [ 3 ] & {$[4]$} & {$[5]$} \\
\hline Retrabalhos & {$[1]$} & {$[2]$} & {$[3]$} & {$[4]$} & {$[5]$} \\
\hline Qualidade no Cliente & {$[1]$} & {$[2]$} & {$[3]$} & [ 4 ] & {$[5]$} \\
\hline Desenvolvimento de Novos Produtos & {$[1]$} & {$[2]$} & {$[3]$} & {$[4]$} & {$[5]$} \\
\hline Endividamento & {$[1]$} & [2] & {$[3]$} & [4] & {$[5]$} \\
\hline Estoques & [ 1$]$ & [2] & [3] & [4] & {$[5]$} \\
\hline
\end{tabular}

\section{QUANTO A ABORDADEM ESTRATEGICA DOS DADOS PLANEJADOS.}

4.1 Como são disseminadas a Visão, Política, Diretrizes e Metas da Produção:

( ) Há consenso entre os gestores de cada área e as definições da diretoria que, são transmitidas para toda a organização explicando os motivos e metas a serem alcançadas, tendo um controle diário do planejado com o realizado.

( ) Existe um planejamento anual de metas e objetivos, que são transmitidas para as áreas envolvidas na meta, tendo um monitoramento freqüente e tomada de ações no caso do não atendimento das metas.

( ) As definições de metas e estratégias são feitas pela diretoria sendo que a execução delas, são conduzidas diretamente entre chefe e o subordinado.

( ) As atividades são divulgadas através de informativos mensais ou extraordinários, não tendo o envolvimento do pessoal da produção.

4.2 Considerando a resposta anterior, todos os planos, metas e indicadores de resultado da produção são compilados e apresentados para os colaboradores utilizando-se de:

( ) Balanced Scorecard - BSC

( ) Sistema de informática Integrado - Enterprise Resource Planning 
( ) Planilha Excel elaborada pelo própria empresa

( ) Painel de Metas alcançadas dispostas em área de comum acesso

( ) Outra forma:

4.3 De acordo com o monitoramento do planejamento da produção, a empresa pode afirmar que os planos e indicadores monitorados pela empresa, também são controlados pelos programas de gerenciamento de qualidade, integrando os resultados da qualidade com a estratégia da empresa.

( ) Sim, todos os planos e indicadores são os mesmos, unificando os programas de qualidade e gerencial.

( ) Sim, mas somente para alguns indicadores, apenas aqueles que dizem respeito a qualidade do produto.

( ) Não, os indicadores do setor de qualidade são diferentes aos da produção devido terem objetivos diferentes dentro da empresa.

( ) Não sei pois tenho acesso somente aos meus planos e indicadores.

4.4 De que forma são promovidas as melhorias no processo produtivo.

( ) São realizadas diversas atividades que buscam melhoria contínua em aspectos identificados e significativos, mantendo o foco das ações dentro de um planejamento geral de melhorias necessárias e desejadas.

( ) Existem diversas atividades de melhorias. As equipes definem metas, atividades e prazos onde são empregadas ferramentas de identificação de problemas e são solucionadas através de técnicas como PDCA, TQM, Kaizen, etc.

( ) As atividades são espontâneas de toda empresa mas as principais ações vem do setor de qualidade que são as maiores representações de melhoria contínua. Outras também podem acontecer mas não são expressivas.

( ) Existe facilidade de se apontar necessidades de melhorias embora não tenha um tratamento especifico para o tratamento dessa ações.

( ) Não existe uma sistemática definida para melhorias, toda sugestão é bem vinda e pode ser executada de acordo com a disponibilidade de recursos.

4.5 Enumere de acordo com o grau de importância atribuído por você ao item analisado como 1 (Concordo totalmente), 2 (Concordo), 3 ( Não concordo e nem discordo), 4 ( Discordo) e 5 ( Discordo Totalmente).

Para a organização, o fechamento de pedidos de vendas ocorrem devido a excelência conquistada nos itens abaixo:

\begin{tabular}{|c|c|c|c|c|c|}
\hline Qualidade da Matéria Prima aplicada & {$[1]$} & {$[2]$} & {$[3]$} & {$[4]$} & {$[5]$} \\
\hline Preço de Venda abaixo do mercado & {$[1]$} & {$[2]$} & {$[3]$} & {$[4]$} & {$[5]$} \\
\hline Propaganda e publicidade & {$[1]$} & {$[2]$} & {$[3]$} & {$[4]$} & {$[5]$} \\
\hline Alta tecnologia na empresa & {$[1]$} & {$[2]$} & {$[3]$} & {$[4]$} & {$[5]$} \\
\hline Marca bem definida & {$[1]$} & {$[2]$} & {$[3]$} & {$[4]$} & {$[5]$} \\
\hline Custo baixo de produção & {$[1]$} & {$[2]$} & {$[3]$} & {$[4]$} & {$[5]$} \\
\hline Rapidez na entrega & {$[1]$} & {$[2]$} & {$[3]$} & {$[4]$} & {$[5]$} \\
\hline Formação técnica dos colaboradores & {$[1]$} & {$[2]$} & {$[3]$} & {$[4]$} & {$[5]$} \\
\hline Baixa concorrência de mercado & {$[1]$} & {$[2]$} & [3] & [4] & {$[5]$} \\
\hline
\end{tabular}

\section{QUANTO AO DESDOBRAMENTO DOS PLANOS EM AÇÕES E INDICADORES}

5.1 O planejamento utilizado pela organização é:

( ) Um Plano de Negócios onde temos bem delimitado todas as diretrizes estratégicas, desdobrando em planos menores que irão alimentar o quadro de metas da empresa. 
( ) O Desdobramento pelas Diretrizes onde cada diretor terá sua meta maior desdobrada em novas metas que deverão ser alcançadas pelos seus subordinados.

( ) O Planejamento Estratégico onde cada gerente é responsável por elaborar um Plano de atendimento as suas metas.

( ) Os planos são traçados de acordo com nossa necessidade mas não temos um modelo a ser seguido.

( ) Outra:

5.2 Como você classificaria a empresa em relação ao fator dominante nos processos produtivos, visando manter um planejamento adequado de produção com um controle eficaz de resultados.

( ) O fator dominante na organização é a integração, pois todos os processos são planejados e controlados via sistema com o uso de softwares ou planilhas.

( ) O fator dominante no planejamento e controle de produção é a utilização de ferramentas de qualidade que irão realimentar o sistema produtivo de gestão através de indicadores que irão gerar novos planejamentos.

( ) O fator dominante no planejamento e controle da produção é o desdobramento das metas, onde uma meta maior é sempre dividida em metas menores, facilitando assim o sua execução e controle da mesma.

( ) Não temos um fator dominante já que a empresa não possui um planejamento e controle de suas ações.

( ) Outro fator. Especificar:

5.3 Quais filosofias/técnicas que a empresa utiliza, com efeitos sobre o sistema de produção da empresa, especialmente para prevenir ou resolver problemas do sistema produtivo.

\begin{tabular}{|l|l|l|l|}
\hline & Just-in-time & & Qualidade Total \\
\hline & Reengenharia & & Kenchmarking \\
\hline & Kanban & & Troca rápida de Ferramentas \\
\hline & Poka Yoke & & ISO 9000 \\
\hline & Manutenção Preventiva Total (MPT) & & Não utiliza nenhuma técnica/filosofia \\
\hline
\end{tabular}

Outra, especificar:

\section{Dados dos Autores:}

\section{Nome completo: Everaldo Antonio Rutana Pereira}

Filiação institucional: Pontifícia Universidade Catolica do Paraná - PUCPR

Departamento: Programa de Pós-Graduação em Engenharia de Produção e Sistemas - PPGEPS

Função ou cargo ocupado: Professor Assistente

Endereço completo para correspondência (bairro, cidade, estado, país e CEP): Rua Imaculada

Conceição $n^{0}$ 1155, Bairro Prado Velho, Curitiba, Paraná, Brasil, CEP 80215-901

Telefones para contato: (41) 32712579

e-mail:everaldo@rodoparana.com.br 
Nome completo: Silvana Pereira Detro

Filiação institucional: Pontifícia Universidade Catolica do Paraná - PUCPR

Departamento: Programa de Pós-Graduação em Engenharia de Produção e Sistemas - PPGEPS

Função ou cargo ocupado: Mestranda

Endereço completo para correspondência: Rua Imaculada Conceição no 1155, Bairro Prado Velho,

Curitiba, Paraná, Brasil, CEP 80215-901

Telefones para contato: (41) 32712579

e-mail: silvana.detro@pucpr.br

Nome completo: Edson Pinheiro de Lima

Filiação institucional: Pontifícia Universidade Catolica do Paraná - PUCPR/ Universidade

Tecnológica Federal do Paraná - UTFPR

Departamento: Programa de Pós-Graduação em Engenharia de Produção e Sistemas - PPGEPS /

Departamento Acadêmico de Eletrotécnica - DAELT

Função ou cargo ocupado: Professor Titular / Professor Associado

Endereço completo para correspondência (bairro, cidade, estado, país e CEP): Rua Imaculada

Conceição no 1155, Bairro Prado Velho, Curitiba, Paraná, Brasil, CEP 80215-901

Telefones para contato: (41) 32712579

e-mail: e.pinheiro@pucpr.br

\section{Nome completo: Sergio Eduardo Gouvea da Costa}

Filiação institucional: Pontifícia Universidade Catolica do Paraná - PUCPR / Universidade

Tecnológica Federal do Paraná - UTFPR

Departamento: Programa de Pós-Graduação em Engenharia de Produção e Sistemas - PPGEPS /

Departamento Acadêmico de Eletrotécnica - DAELT

Função ou cargo ocupado: Professor Titular / Professor Adjunto

Endereço completo para correspondência: Rua Imaculada Conceição no 1155, Bairro Prado Velho,

Curitiba, Paraná, Brasil, CEP 80215-901

Telefones para contato: (41) 32712579

e-mail: s.gouvea@pucpr.br

Enviado em: 15/06/2011

Aprovado em: 18/05/2012 